Patenting Fast and Slow: Examiner and Applicant Use of Prior Art

Shine Tu

Follow this and additional works at: https://researchrepository.wvu.edu/law_faculty

Part of the Intellectual Property Law Commons 


\title{
PATENTING FAST AND SLOW: EXAMINER AND APPLICANT USE OF PRIOR ART *
}

\author{
SHINE SEAN TU*
}

\begin{abstract}
Previous studies have shown that an applicant's ability to obtain a patent is inexorably linked to the random assignment of a patent examiner. ${ }^{1}$ However, not all patent examiners are created equal. Some patent examiners allow patent applications quickly within just one or two Office Actions, resulting in only a few months of substantive patent prosecution. In contrast, other patent examiners constantly reject patents applications, which can result in unnecessarily delaying prosecution and years of substantive patent prosecution. This study focuses on how different examiners use prior art rejections to prolong or compact prosecution.

Prior art rejections are one of the most important hurdles to obtaining a patent. Specifically, the use of prior art rejections directly impacts the time and effort it takes to obtain a patent. Anticipation and obviousness rejections are usually the most important and difficult
\end{abstract}

\footnotetext{
- Permission is hereby granted for noncommercial reproduction of this Article in whole or in part for education or research purposes, including the making of multiple copies for classroom use, subject only to the condition that the name of the author, a complete citation, and this copyright notice and grant of permission be included in all copies.

* Professor, West Virginia University College of Law. Sincere thanks to the many readers who offered comments on earlier drafts, including participants at the 2019 Mid-Atlantic Patent Worksin-Progress Conference, Jonas Anderson, Chris Cotropia, Dmitry Karshtedt, Aman Begru, Megan LaBelle, Johnathan Sarnoff, and participants at the 2020 Three Rivers IP \& Tech Law Colloquium, Michael Madison, Bryan Choi, James Dilmore, Brian Frye, Emily Michiko Morris, Aaron Perzanowski, Guy Rub, and Mark Schultz. Additionally, the author thanks the Program Evaluation and Research Center at West Virginia University, as well as Chen Zhao for providing the statistical analysis. The author would also like to thank Nicholas F. Stump for his detailed review and comments. Finally, a sincere thanks to Michael Madison for a brilliant title. This work was funded in part by the generous support of the West Virginia University College of Law Hodges Research Fund.

1 See Sean Tu, Luck/Unluck of the Draw: An Empirical Study of Examiner Allowance Rates, 2012 STAN. TECH. L. REV. 10, 14 (2012) [hereinafter Tu, Luck/Unluck of the Draw]; see also Shine Sean Tu, Three New Metrics for Patent Examiner Activity: Office Actions per Grant Ratio (OGR), Office Actions per Disposal Ratio (ODR), and Grant to Examiner Ratio (GER), 100 J. PAT. \& TRADEMARK OFF. SOC'Y 277 (2018) [hereinafter Tu, Three New Metrics for Patent Examiner Activity]; see also Michael D. Frakes \& Melissa F. Wasserman, Is the Time Allocated to Review Patent Applications Inducing Examiners to Grant Invalid Patents? Evidence from Microlevel Application Data, 99 REV. ECON. \& STAT. 550 (2017), https://content.ebscohost.com/ ContentServer.asp? $\mathrm{T}=\mathrm{P} \& \mathrm{P}=\mathrm{AN} \& \mathrm{~K}=124164320 \& \mathrm{~S}=\mathrm{R} \& \mathrm{D}=\mathrm{buh} \&$ EbscoContent=dGJyMMvl7ES ep7E4v\%2BbwOLCmsEiep7BSsKu4Sq6W xWXS\&ContentCustomer=dGJyMPGsrlC0rrdKuePf gey 44 Dt6flA [https://perma.cc/NU6K-KXPZ].
} 
obstacles to overcome before obtaining a patent. ${ }^{2}$ This empirical study focuses on how different types of examiners (i.e., fast high volume versus slow/low volume) use prior art rejections to either compact or delay prosecution. Since patent examination is dependent on both examiner and applicant behavior, this study also evaluates how applicants respond to these prior art rejections to also prolong or compress prosecution. Unlike many studies, this is the first one that evaluates patent quality based on both individual examiner characteristics, as well as applicant behavior at the patent prosecution level.

In sum, high volume, average volume, and low volume examiners issued a patent in approximately 1.64 years, 3.07 years, and 5.85 years, respectively. Thus, high volume examiners issue patents almost twice as quickly as average volume examiners and more than three times as fast as low volume examiners. This large difference can represent a huge investment in both capital and time for the applicant, as well as for the PTO.

Additionally, this study finds that low volume examiners reject applications based mainly on obviousness, issuing over four times as many obviousness rejections per Office Action as compared to high volume examiners. Furthermore, low volume examiners issue five times as many Section 102(a), (g), or (e) rejections and two times as many Section 102(b) rejections. And applicants most commonly make a "missing element" argument to traverse a slow examiner's Section 102(a), (g) or (e) rejection at three times the rate of a fast examiner. This type of traversal strategy relies on the examiner's misunderstanding of either the art or the claimed invention. Similarly, applicants also use the "missing elements" argument to traverse a slow examiner's Section 103 rejection at five times the rate of a fast examiner. Finally, applicants are also three times more likely to use a "teaching away" or "unexpected results" argument to traverse a slow examiner compared to a fast examiner. Both of these arguments can again rely on either the examiner's misunderstanding of the prior art or a misunderstanding of the claimed invention.

This study demonstrates that different types of examiners use different strategies to maximize their "counts." Specifically, low volume examiners will generally reject applications, creating lengthy prosecution histories and forcing the applicant to narrow claims, while showing a misunderstanding of either the prior art and or the claimed invention. In contrast, high volume examiners will usually only make one

2 See Stephen Yelderman, Prior Art in the District Court, 95 NOTRE DAME L. REV. 837, 840 (2019), ndlawreview.org/wp-content/uploads/2020/01/7.-Y elderman.pdf [https://perma.cc/M $77 \mathrm{R}$ S99A] ("[A]mong all [the] patent cases filed in 2008 and 2009, 154 summary judgment motions were filed on the basis of anticipation ...."). 
rejection before allowing the case, thus creating a small prosecution history with only small amendments to the claims.

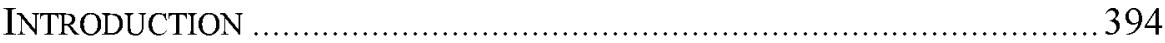

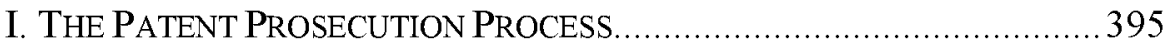

A. PTO Efforts to Improve Prior Art Searching and Analysis 395

B. Patent Examination Process ............................................... 395

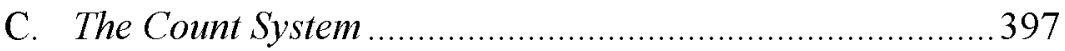

D. Patent Examiner Incentives Count Maximization Strategies

1. Strategy 1: High Allowance Rate Count Maximization Strategy - One Office Action with Minimal Claim Amendments Then Allowance.

2. Strategy 2: Low Allowance Rate Count Maximization Strategy - Several Office Actions with RCEs and CONs with Many Rejections ................................................ 401

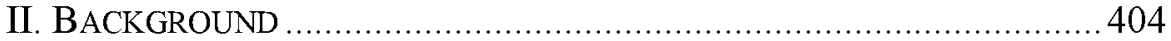

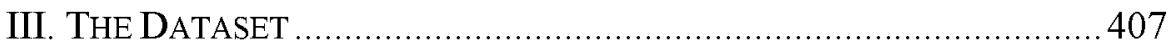

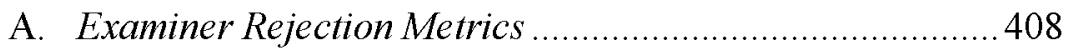

B. Applicant Response Metrics ......................................... 408

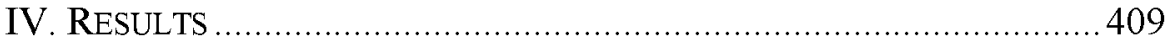

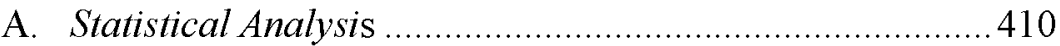

B. General Prosecution History Statistics ............................ 411

1. Priority Documents Metrics........................................ 411

2. Length of Office Actions and Responses ..................... 411

C. Examiner Rejection Statistics Based on 35 U.S.C. $\$ \S 102$ and 103-Anticipation and Obviousness Based on Prior Art ... 412

D. Applicant Responses to 35 U.S.C. $\S 102$-Anticipation Rejections Based on Prior Art ...................................... 414

1. Applicant Responses to 35 U.S.C. $\S 102(\mathrm{a})$, (g), or (e)Anticipation Rejections Based on Prior Art

2. Applicant Responses to 35 U.S.C. § 102(b) -Anticipation Rejections (Statutory Bar) Based on Prior Art ............. 416

E. Applicant Responses to 35 U.S.C. $\S 103$-Anticipation Rejections Based on Prior Art..................................... 418

1. 35 U.S.C. $\S 103-$ Claim Amendment Traversal Argument ....................................................... 418

2. 35 U.S.C. $\$ 103-$ Missing Element(s) Traversal Argument

3. 35 U.S.C. $\S 103$ - No Motivation to Combine Traversal

Argument

4. 35 U.S.C. $\S 103$-Use of 131 and 132 Declarations .... 421

5. 35 U.S.C. $\S 103$-Teaching Away Traversal Strategy. 421 


\section{35 U.S.C. $§ 103$-Unexpected Results Traversal Strategy}

7. 35 U.S.C. $\$ 103$-Prior Art Not Enabled/No Motivation to Modify Traversal Strategy ....................................... 423

F. Implications and Possible Solutions.................................424

1. Target Examiners Who Deviate Drastically from the Norm for Enhanced Review by Quality Assurance...... 425

2. Deduct Counts for Bad Rejections and Add Counts for Difficult Applicants 425

3. Alert Examiners When Their Issued Cases are Litigated 426

4. Bifurcation of the Patent Searching and the Office Action Writing Process.

\section{INTRODUCTION}

Preventing examination errors at the patent office should always be an aspirational goal for all examiners at the United States Patent and Trademark Office (PTO). However, quality prosecution also includes a temporal factor. Balancing speed with patent quality should be the goal of the PTO. It has previously been shown, however, that the patent examination process is not homogenous. ${ }^{3}$ Specifically, there are two distinct populations of examiners. First, there are high volume examiners who issue, on average, more than fifty patents per year. Second, there are low volume examiners who issue, on average, less than five patents per year.

The main empirical question this Article explores is how high volume ("fast") and low volume ("slow") examiners behave differently from average volume examiners when using prior art rejections. Previous studies have argued that retaining experienced examiners is one crucial key to solving the patent quality crisis. ${ }^{4}$ This Article attempts to determine whether this argument is true by examining how different types of experienced examiners use prior art to prolong or expedite prosecution.

Part $I$ is a brief summary of the patent examination process and the examiner count system that is associated with the examination process.

\footnotetext{
${ }_{3}^{3}$ See Tu, Luck/Unluck of the Draw, supra note 1; see also Tu, Three New Metrics for Patent Examiner Activity, supra note 1; see also Mark A. Lemley \& Bhaven Sampat, Examiner Characteristics and Patent Office Outcomes, 94 REV. ECON. \& STAT. 817 (2012), https:// law.stanford.edu/wp-content/uploads/sites/default/files/publication/270628/doc/slspublic/rest_a_ 00194.pdf [https://perma.cc/3DU3-8UVM].

4 See ADAM B. JAFFE \& JOSH LERNER, INNOVATION AND ITS DISCONTENTS: HOW OUR BROKEN PATENT SYSTEM IS ENDANGERING INNOVATION AND PROGRESS, AND WHAT TO DO ABOUT IT (2004).
} 
Part II provides the background for and describes the previous literature in this area. Part III describes the new dataset created for this study, as well as the strengths and limitations of the dataset. Part IV describes the results of this study. Part $\mathrm{V}$ concludes and discusses the potential implications of policy changes to the PTO examination procedure.

\section{The Patent Prosecution Process}

The PTO currently is staffed with 9,614 patent examiners and 12,652 employees. ${ }^{5}$ In recent years, the examiner corps has allowed over 300,000 patents per year. ${ }^{6}$ Additionally, the PTO has over $\$ 3.38$ billion in assets from fees generated in association with the PTO. ${ }^{7}$ Unquestionably, the PTO commands a large workforce with an enormous pool of resources. However, even in light of its workforce and budget, the backlog of patent applications still stands at over 497,164 applications. ${ }^{8}$

\section{A. PTO Efforts to Improve Prior Art Searching and Analysis}

The PTO provides its examiners with many resources to assist with prior art searches. ${ }^{9}$ Specifically, the PTO makes experts available to each examiner "to help with search strategies based on technology and classification, as well as assistance with available search tools." 10 Furthermore, the office is examining how new technologies such as artificial intelligence can be used to help locate and retrieve relevant prior art for examiners. ${ }^{11}$ Additionally, the PTO tested new processes to leverage examiners in foreign offices to help U.S. examiners use collaborative searches for prior art. ${ }^{12}$

\section{B. Patent Examination Process}

When an application is sent to the PTO, it is reviewed to ensure all procedural requirements are met for a filing date. ${ }^{13}$ Applications are then

\footnotetext{
5 U.S. PATENT \& TRAdEMARK OFFICE, PERFoRMANCE AND ACCOUNTABILITY REPORT 12 fig. 3 (2019), https://www.uspto.gov/sites/default/files/documents/USPTOFY 19PAR.pdf [https://perma. cc/WKE5-WKMZl.

6 See id. at 169 tbl.6.

$7 \mathrm{Id}$. at 30 .

8 See id. at 169 tbl.5 (identifying in the 2019 "Summary of Total Pending Patent Applications" 442,591 applications as "Awaiting First Action by Examiner" and 54,573 applications as "Undocketed").

9 See id. at 54 .

$10 \mathrm{Id}$.

$11 \mathrm{Id}$.

$12 \mathrm{Id}$.

13 See U.S. Dep'T of Commerce, Patent \& Trademark OfFice, Manual of Patent EXAMINING PROCEDURE $\S 506$ (9th ed., Rev. 8, Jan. 2018) [hereinafter MPEP]; see also 37 C.F.R. $\S 1.53$ (2019), https://www.govinfo.gov/content/pkg/CFR-2019-title37-voll/pdf/CFR-2019-title37 -voll-sec1-53.pdf [https://perma.cc/4TG3-SP6A].
} 
sorted for examination by an "Art Unit."14 Each art unit has a group of examiners who are related by similar technologies. ${ }^{15}$ Once in the art unit, a supervisory patent examiner (SPE) will then assign applications, for the most part randomly, ${ }^{16}$ to a reviewing examiner. The reviewing examiner can be either a primary examiner or secondary examiner. A primary examiner is usually more experienced (typically with more than five years at the patent office), has the ability send out actions to the applicant with limited review (signatory authority), and is not under constant supervision. In contrast, a secondary examiner is a junior examiner, who usually has less than five years at the PTO, cannot send out actions to the applicant without review, and is under the supervision of a primary examiner.

After applications are assigned, examiners review the specification and closely examine the claims. The reviewing examiner then conducts a search for prior art that may render the application unpatentable (usually due to anticipation or obviousness). Examiners search within databases such as prior U.S. patents or applications, foreign patents, and/or nonpatent literature, including scientific or technical journals. The reviewing examiner then assesses the novelty and non-obviousness of the claims in light of the prior art that was found and the prior art disclosed by the

14 "The term, Art Unit, refers to the group of professionals responsible for a cluster of related patent art." Patent Classification, USPTO: PATENTS, https://www.uspto.gov/patents-application-process/ patent-search/classification-standards-and-development [https://perma.cc/36KR-HDS8]

15 See Patent Technology Centers Management, USPTO: PATENTS, https://www uspto.gov/patent/ contact-patents/patent-technology-centers-management [https://perma.cc/E6GY-YV9S] (indicating the types of technology that correspond with each specific Technology Center). "Art Units are currently identified by a four digit number . . . Patent Classification, supra note 14. Each hundreds unit - i.e., $1600,1700,2100,2400,2600,2700,2800,2900,3600,3700$-represents a large technology group. See Patent Technology Centers Management, supra. For example, Technology Center 1600 examines patent applications involving biotechnology and organic chemistry, while Technology Center 2100 examines patent applications concerning computer architecture software and information security. Id. Moreover, each tens unit-i.e., 10, 20, 1630,40, 50,60 represents a smaller, more narrowly focused category of the Technology Center's much broader Art Unit. See, e.g., TC 1600 Management Roster: Biotechnology and Organic Chemistry, USPTO: PATENTS, https://www.uspto.gov/patent/contact-patents/tc-1600-management-roster [https://perma.cc/MQB3-MM3T]. For example, while 1610 examines patent applications claiming organic compounds, 2110 examines patent applications claiming computer error control, reliability, and/or control systems. See id.; see also TC 2100 Management Roster: Computer Architecture and Software, USPTO: PATENTS, https://www.uspto.gov/patent/contact-patents/tc-2100-managementroster [https://perma.cc/G39D-T32K]. Finally, the unit digit-i.e., $0,1,2,3,4,5,6,7,8,9-$ represents the specific class of technology examined by each individual Art Unit in a Technology Center. See, e.g., Classes Arranged by Art Unit: Art Units 1611-1763, USPTO: PATENTS, https:// www.uspto.gov/patents-application-process/classes-arranged-art-unit-art-units-1611-1763 [https:/ /perma.cc/EPF7-GAS8]. For example, Art Unit 1611 examines patent applications for drug, bioaffecting, and body treating compositions, while Art Unit 2115 examines patent applications for electrical computers and digital data processing systems. See id.; see also Classes Arranged by Art Unit: Art Units 1764-2691, USPTO: PATENTS, https://www.uspto.gov/patents-application-process/ classes-arranged-art-unit-art-units-1764-2691 [https://perma.cc/D23U-29MK]

16 "SPEs for the most part assign[] applications ... to particular examiners on the basis of the last digit of the application serial number." See Lemley \& Sampat, supra note 3, at 822. However, "[a] minority of supervisory examiners assign[] applications on the basis of docket management, giving the oldest unassigned application to an examiner when that examiner [has] finished examining a prior application." Id. 
applicant. Furthermore, the reviewing examiner will determine if the claims have written support, utility, and are enabled.

If there is no prior art and the claims are properly described and enabled, the examiner will issue a notice of allowance. However, first action allowances are a relatively rare occurrence. ${ }^{17}$ More commonly, the examiner will reject the claims for one of the reasons listed above. ${ }^{18}$ The applicant then has no more than six months to respond to the Office Action. Usually, the applicant will take one or both of the following actions: (1) amend the claims to traverse the rejections, and/or (2) traverse the rejection based on scientific or legal arguments.

If the examiner is persuaded by the response, they can allow the case. If the examiner is not persuaded, they can reject using the same rejections as in the first Office Action or reject based on new grounds. Depending on the arguments made by the applicant (and if the examiner finds them persuasive), the examiner can then choose to make their next response either "final" or "non-final." The applicant has six months to choose one of several common options: (1) file a Request for Continued Examination (RCE) to continue examination, essentially continuing prosecution where the examiner left off; (2) file a notice of appeal, appealing the rejections to the Board of Patent Appeals and Interferences (BPAI); (3) abandon the application; or (4) file a continuation application or continuation-in-part (CIP) application. Filing a continuation or CIP application can be done in conjunction with filing an RCE, notice of appeal, or abandonment. The process then repeats itself until a patent is allowed or the applicant abandons the application.

\section{The Count System}

Examiners measure their productivity through the count system, ${ }^{19}$ which is a system that has adapted to new technologies, increased availability of prior art, adjustments in policy and legal interpretations, and a host of other changes. The most recent comprehensive changes were made in 2010 , in an attempt to equally balance productivity and quality along with, to a lesser degree, timeliness and customer service. ${ }^{20}$

17 See Mark A. Lemley \& Bhaven Sampat, Examining Patent Examination, 2010 STAN. TECH. L. REV. 2, 4 tbl.l (2010), https://pdfs.semanticscholar.org/0689/105c94ebelbfed39619la9 lca4c3bf 905c88.pdf [https://perma.cc/AC9Y-Q6NP].

18 See id. (" $86.5 \%$ of the PTO's first office actions were non-final rejections.").

19 For a complete discussion of the count system, see Naira Rezende Simmons, Putting Yourself in the Shoes of a Patent Examiner: Overview of the United States Patent and Trademark Office (USPTO) Patent Examiner Production (Count) System, 17 J. MARShall ReV. InTEll. Prop. L. 32 (2017), https://repository.jmls.edu/cgi/viewcontent.cgi?article=1422\&context=ripl [https:// perma.cc/JAS2-82LN].

$20 \mathrm{Id}$. at 37 . Four elements are used to evaluate an examiner's overall yearly performance: (1) Production (35\%), (2) Quality (35\%), (3) Docket Management (20\%), and (4) Stakeholder Interaction $(10 \%)$. Id. 
Patent examiners are evaluated based on how many "counts" they accrue. Each new patent application can give an examiner 2.0 credits (or counts), allocated according to the figure below:

Figure 1.

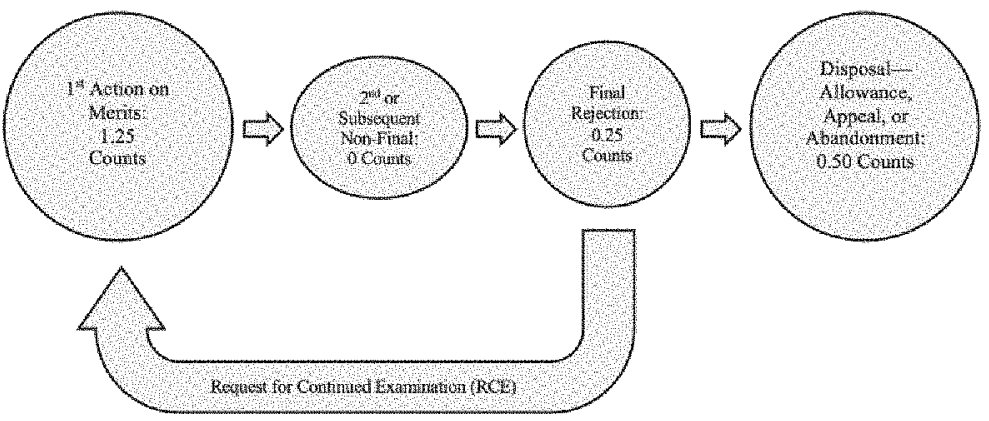

To incentivize examiners to initially perform the best search and provide the most relevant rejections, subsequent applications provide less weight. An RCE is a mechanism by which the PTO can reopen prosecution of a patent application after receiving a final Office Action. When the applicant files their first RCE, the first office on the merits after the RCE is filed will now be worth only 1.00 count instead of 1.25 counts. However, if the examiner allows the case after the FOAM after the RCE, the examiner will receive 3.25 counts $(1.25+0.25+1.00+0.25+0.5)$. After the second RCE is filed, the FOAM after the second RCE will only be worth 0.75 . Accordingly, if the examiner allows the case after the FOAM after the second RCE, the examiner will receive 4.75 counts $(1.25$ $+0.25+1.00+0.25+0.75+0.25+0.5){ }^{21}$ The diminishing counts received from an $\mathrm{RCE}$ can be justified because the examiner is reviewing the same application and should not have to relearn the entire specification.

The sheer numbers of applications and examiners necessitate that the PTO and the Patent Office Professional Association (POPA) use a basic formula to maintain quality standards. ${ }^{22}$ The new count system has created an equation that considers examiners' workload, their experience level, and the complexity of the technology they are examining. After all, examiners with more experience should theoretically be able to work more efficiently, and those who are dealing with especially intricate technologies such as gene therapy will have more research to do than those dealing with fishing lures. ${ }^{23}$

21 See Patent Office Prof'l Ass'n, Patent Examiner Performance Appraisal Plan (PAP) GUIDELINES 5 (2012), http://www popa.org/static/media/uploads/uploads/examiner-papguidelines-04_19_12-508.pdf [https://perma.cc/5FDT-AG96].

22 Formed in $\mathbf{1} 96 \overline{4}$, POPA is an independent union of patent examiners.

23 The PTO suggests, for example, that an examiner might expect to spend 16.6 hours per Production Unit on a fishing lure application but 27.7 hours per Production Unit on technology 
The number of examining hours includes all of the examiners' time for reviewing applications, analyzing the claims, searching and considering prior art, consulting colleagues, writing Office Actions, addressing applicants' responses, and all other related administrative activities. The amount of time an examiner should spend on an application is tied to the technological field, as well as their position in the general schedule (GS) pay scale, with GS-12 representing a Position Factor of 1.0.24

The current formula for determining hours per Production Unit is:

$$
\frac{\text { (\# of Examining Hours) } x \text { (Seniority Factor) }}{\text { (Technology Complexity) }}=\frac{\text { (Counts Needed for Goal) }}{2}
$$

Thus, if two examiners of different seniority levels work the same number of hours in a fortnight in the same art unit and with the same technology complexity, they will have different work expectations. The following example contains two examiners of different seniority (one is a junior examiner of GS-5 and the other a GS-12) who work seventy-two hours within a two-week period and deal with the same Immunotherapy Art Unit:

GS-5: (72 hours $x 0.55$ seniority factor $) /(25.9$ complexity $)=(3.1$ Counts $) / 2$ GS-12: $(72$ hours $x 1.0$ seniority factor $) /(25.9$ complexity $)=(5.6$ Counts $) / 2$

Accordingly, the GS-12 examiner will have an output expectation that is almost double that of the GS-5 examiner.

\section{Patent Examiner Incentives - Count Maximization Strategies}

Like any formulaic system, the count system incentivizes examiners to maximize their number of counts. Thus, the U.S. count

dealing with satellite communication. See U.S. PATENT \& Trademark OFFICE, PATENT QuAlity CHAT: EXAMINATION TIME ANALYSIS 21 (2017), https://www.uspto.gov/sites/default/files/ documents/patent-quality-chat-april-presentation.pdf [https://perma.cc/U6SE-L6UJ]. Note that one Production Unit (PU) equals two "counts." Id. at 22. Seniority is measured using the following chart:

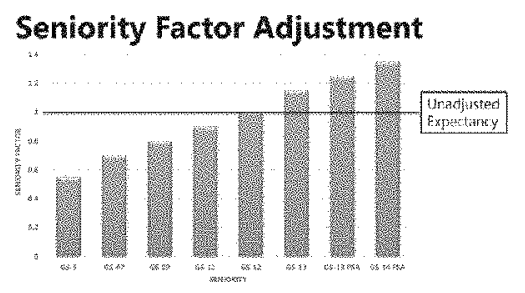

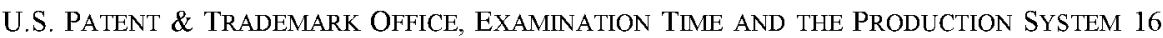
(2017), https://www uspto.gov/sites/default/files/documents/Examination\%20Time\%20and\%20 the\%20Production \%20System.pdf [https://perma.ce/Y65V-NLDK].

24 See PATent Office Prof'L Ass'N, supra note 21, at 3-4. 
system, to a large degree, rewards quantity. There are two main strategies by which an examiner can maximize counts. The first method for count maximization calls for examiners to dispose of a case quickly, either through abandonment or allowance, in one or two Office Actions. If an examiner can quickly get the applicant to allowance (or abandonment) within one or two Office Actions, this will garner many counts for the examiner. The second method for count maximization calls for examiners to maximize counts by cycling through rejections and forcing applicants to file multiple Requests for Continued Examination (RCEs) or continuation applications. This second method calls for more work by the examiner because they are continually coming up with new rejections. This study shows that fast examiners maximize counts by quickly allowing cases ("Strategy 1"), while slow examiners maximize counts by cycling through rejections ("Strategy 2").

1. Strategy 1: High Allowance Rate Count Maximization Strategy - One Office Action with Minimal Claim Amendments Then Allowance

There are incentives and strategies by which an examiner can use rejections to garner additional counts. The first method to maximize counts is to have a large volume of smaller value counts. By allowing many cases after one non-final rejection, these examiners can garner the greatest number of counts with the least amount of effort in the shortest amount of time.

This first strategy for maximizing counts relies on cycling quickly through patent applications by rejecting the application once, and then disposing of the case (i.e., either through allowance or abandonment). Although the examiner does not have control over applicant abandonment, the examiner does have control over allowance. This study finds that examiners who have a high allowance rate may be following this strategy to maximize counts. Examiners who employ this strategy will usually allow more cases and do so with only one or two rejections. Counts are maximized because examiners will get a total of two counts per application. Additionally, by allowing the application after one Office Action, and allowing many applications, the counts are maximized with little applicant resistance. ${ }^{25}$

In addition, the time factor may play a role because senior primary examiners are given a shorter amount of time to review an application than junior examiners or even other primary examiners who just gained signatory authority. ${ }^{26}$ Because senior examiners are required

25 Applicants rarely appeal an allowance.

26 See Frakes \& Wasserman, supra note 1. 
to examine more cases in less time, quick allowance can be the path of least resistance to count maximization.

Previous studies have shown that more experienced primary examiners maximize their counts by quickly allowing cases. ${ }^{27}$ Specifically, many experienced primary examiners allow cases with little to no claim amendments, and have a much higher rate of first action allowances. ${ }^{28}$ These examiners have much less time to review patent applications because more senior examiners are required to garner more counts in less time.

One goal of this study is to determine how experienced examiners are allowing cases by determining how different examiners use prior art rejections to either prolong or compact prosecution. Additionally, this study examines each claim and the prosecution history of each claim to determine if the examiner is allowing "high quality" patents.

2. Strategy 2: Low Allowance Rate Count Maximization Strategy-Several Office Actions with RCEs and CONs with Many Rejections

The second strategy for count maximization is more complex. Examiners in this group maximize their counts by rejecting the application and forcing applicants to file RCEs or continuation applications. Examiners can garner more than $150 \%$ of the credits $(3.25$ counts compared to 2.00 counts) if they allow the case after an RCE. ${ }^{29}$

Accordingly, examiners may maximize their counts by following a rejection/RCE strategy. If an examiner generates a continuous stream of rejections, they can maximize their counts by forcing the applicant to either file an RCE or continuation applications (CONs, CIPs, and/or DIVs). Each new family member creates a new stream of counts. Thus, if the examiner continues to reject the application, the applicant may be forced to file child applications, which allows the examiner to garner even more counts in the future. Alternatively, the applicant can file an appeal. No counts are credited to the examiner if rejections are reversed on appeal, and the application will simply return to its prior stage of prosecution. However, applicants do not typically appeal their applications because of increased time delay and higher costs.

There are two factors that compound the problem and give the examiner even more incentive to reject. First, RCE and continuation practice allow an examiner to spend less time to issue more rejections. Second, examiners face less scrutiny when issuing rejections as compared

27 See $\mathrm{Tu}$, Luck Unluck of the Draw, supra note 1, at 14; see also Tu, Three New Metrics for Patent Examiner Activity, supra note 1.

28 See Lemley \& Sampat, supra note 3.

29 See discussion supra Section I.C. 
to allowing an application. As discussed below, this scrutiny issue can be especially pronounced when comparing experienced examiners with junior examiners.

First, examiners may be incentivized to reject applications because there is a quota system in place. This quota system decreases the amount of time examiners can spend on an application as they accumulate experience at the PTO. RCE and continuation practice can allow examiners to garner more counts in a shorter amount of time. The specification of a continuation application (and RCE) is substantially similar or identical to the parent application. Thus, if an applicant is forced to file a continuation application or RCE, the examiner should need much less time to review and understand the claimed technology, because the review was already completed in the parent application. Accordingly, it should require less work for the examiner to come up with (1) art rejections because the examiner need only complete a new search and review any new pieces of $\operatorname{art}^{30}$ and (2) written description/enablement rejection $\mathrm{s}^{31}$ because the specification is identical to the parent application. Therefore, forcing applicants to file RCEs and/or continuation applications allows the examiner to spend less time to garner more counts.

One might assume that this time pressure would force more senior examiners to reject applications, thereby maximizing counts while reducing the time needed to review applications. Interestingly, most senior primary examiners do not avail themselves of this strategy. In contrast, this strategy is used by many secondary examiners and, to a large extent, by examiners who are most junior. Previous studies have shown that less experienced secondary examiners maximize their counts by issuing many more rejections and fewer patents. ${ }^{32}$ This strategy does require the examiner to come up with multiple rejections; however, this issue is mitigated because secondary examiners are given much more time to work on a case as compared to their primary examiner counterparts.

Second, this rejection strategy may be particularly attractive to secondary (junior) examiners who are subjected to more scrutiny when they allow a case. To allow a case, the secondary examiner: (1) needs to get approval from the primary examiner working with them, and then (2)

\footnotetext{
30 An examiner can more efficiently understand the prior art because they have already read some of that art in their previous rejections. Additionally, the examiner does not need to review the applicant's specification to compare it to the prior art reference, as this should have been done previously in the parent application.

31 If an applicant makes a claim amendment, the examiner does not need to review the specification because, in examining the parent application, they already should have done so.

32 See Lemley \& Sampat, supra note 3 , at 822 .
} 
the application needs to go for quality review before the patent issues. In contrast, a rejection is only reviewed by the primary examiner.

Additionally, there are minimal consequences or punishments when bad rejections are issued, hence there may be a censoring toward rejections. In fact, a barrage of rejections may actually benefit the junior examiner, as it may seem that the examiner has done a complete and thorough job. On the surface, a voluminous Office Action that is based on many prior art rejections may signal a comprehensive prior art search with an exhaustive set of rejections. However, one must delve much deeper into the Office Action and specific rejections to determine if the examiner was rigorous or repetitive in their rejections. Furthermore, when an application is rejected, it usually does not go to Quality Assurance, and thus avoids review.

In contrast, the consequences for an erroneous allowance can be significant. An examiner may lose privileges or suffer institutional ridicule when issuing bad patents. ${ }^{33}$ Furthermore, under the "Second Pair of Eyes" review program, there has been anecdotal evidence that two "reversals" could result in termination. ${ }^{34}$ Importantly, the relationship between the supervising primary and secondary examiner may be damaged if the supervising examiner catches too many errors by the secondary examiner. Specifically, if the supervising primary examiner becomes wary of the secondary examiner's erroneous allowances, the supervising examiner may scrutinize the work of the secondary examiner much more carefully before allowing future applications. Furthermore, if an error is caught by Quality Assurance, then the repercussions for the junior examiner may even be more substantial.

Finally, the most junior examiners have one additional, but very important, reason to default to rejection of applications. Specifically, junior examiners cannot join the Patent Office Professional Association unless they have two years of service. Once examiners become members of POPA, it becomes increasingly difficult for the PTO to terminate their employment. Accordingly, junior examiners may be more willing to reject claims at a higher rate to avoid unfavorable reviews, thereby lowering their chances of getting fired within the first two years.

It is true that applicants have the ability to appeal an examiner's decision to the PTAB or further to the U.S. District Court for the District

33 See Daniel Wright, Patently Silly: From the Collapsible Walker to the INCINERATING TOILET, THE CRAZIEST INVENTIONS EVER DEVISED (2009); see also RICK FEINBERG, PECUliar PATENTS: A COlLECTION OF UNUSUAL AND INTERESTING INVENTIONS FROM THE FLES OF THE U.S. PATENT OFFICE (1994).

34 See Warren Woessner, Second Pair of Eyes Review Is the Wicked Witch Really Dead?, PATENTS4LIFE (Oct. 23, 2009), http:/www patents4life.com/2009/10/second-pair-of-eyes-reviewis-the-wicked-witch-really-dead/ [https://perma.cc/86T6-VFTD] ("One Examiner . . . [explained] that if he received two 'reversals' from all SPOE [(Second Pair of Eyes)] review, he could be fired."). 
of Columbia and then to the Federal Circuit. However, this avenue may be expensive and unavailable to those inventors who are trying to patent their invention on a budget. ${ }^{35}$ Those inventors who are using the patent system as a signal to obtain venture capital funding may impair their chances of getting funding if they (1) fail to obtain a patent, (2) continue to fail to obtain a patent after PTAB and/or judicial review, and (3) fail to generate a strong patent portfolio. ${ }^{36}$

Some commentators argue that this trend suggests that junior examiners are doing more work and rejecting applications with more rigor early in their career, while doing less work and allowing more patents as their tenure increases. ${ }^{37}$ This argument makes logical sense because senior examiners are given much less time to review applications when compared to their junior counterparts. This Article argues, however, that this trend is mainly a function of the count system and the incentives it generates. Specifically, for some examiners, there are few repercussions (and actually some benefits) for generating Office Actions with numerous rejections. In fact, under the current count system, some examiners may have an incentive to default to the rejection of applications. In fact, examiners who issue Office Actions with a litany of rejections may be considered more thorough in their examination process.

\section{BACKGROUND}

The Patent and Trademark Office faces two problems when it comes to patent examination: It needs to avoid (1) issuing too many invalid/low quality patents, and (2) issuing too few valid/high quality patents. By focusing on prior art rejections, this study attempts to dissect the underlying examiner behavior that may account for this behavior. Specifically, this study attempts to quantify examiner behavior by reviewing actual examiner rejections and allowances. Accordingly, the Author reviewed three hundred patents from three groups of examiners: (1) low volume allowance rate primary examiners (examiners that allow less than five patents per year); (2) average volume allowance rate

\footnotetext{
35 PTO fees include payment for filing a notice of appeal, requesting an oral hearing, and forwarding an appeal to the Patent Trial and Appeals Board, which costs approximately $\$ 4340$ in total $(\$ 800+\$ 1300+\$ 2240)$. See USPTO Fee Schedule, USPTO: LEARNING \& RESOURCES, https: //www.uspto.gov/learning-and-resources/fees-and-payment/uspto-fee-schedule\#Patent $\% 20 \mathrm{Fees}$ [https://perma.cc/MT5L-AAZ9] (last revised Mar. 1, 2020). These costs do not include the thousands of dollars in attorneys' fees that usually are associated with an appeal to the PTAB. 36 See Clarisa Long, Patent Signals, 69 U. CHI. L. REV. 625 (2002), https://chicagounbound. uchicago.edu/cgi/viewcontent.cgi?article $=5135 \&$ context=uclrev [https://perma.cc/QQ7Y-C93X] (discussing the use of patents as a means to credibly publicizing information); see also Gideon Parchomovsky \& R. Polk Wagner, Patent Portfolios, 154 U. PA. L. REV. 1 (2005), https:// scholarship.law.upenn.edu/cgi/viewcontent.cgi?article $=1294 \&$ context=penn_law_review [https: $/ /$ perma.cc/K35P-95MY] (focusing on the aggregation of patents into patent portfolios as a separate function for patents).

37 See Lemley \& Sampat, supra note 3, at 822; see also Frakes \& Wasserman, supra note 1.
} 
primary examiners (as determined by the average allowance rate for the specific technology center); $;^{38}$ and (3) high volume allowance rate primary examiners (examiners that allow more than fifty patents per year). This study focuses on the "working examiner," which is the primary examiner who worked alone on the patent application.

Previous studies have shown that not all patent examiners behave in a similar fashion. For example, Lemley and Sampat have shown that more experienced examiners cite less prior art and are more likely to grant patents. ${ }^{39}$ Lemley and Sampat show that these effects are not due to selection for "easier" applications, but possibly due to selective retention, examiner tenure, technological obsolescence, or the quota system. ${ }^{40}$

One of the underlying themes of this study is that more rejections will result in "better/higher quality" patents. In addition, the more prior art rejections that the invention has overcome, the stronger the patent. It is true that more rejections may greatly narrow the scope of the patent, such that more information disclosed in the application remains unclaimed. This may enhance social welfare, as more of the disclosure is dedicated to the public. However, it may also be true that the applicant did not need to narrow the claims in the first place, if in fact the full scope of the original claims was novel, non-obvious, useful, enabled, and fully described. This study attempts to address this issue by reviewing the prosecution histories from different types of examiners to determine if there is poor or inconsistent examination.

The Lemley and Sampat study is both more and less comprehensive than this study. It is more comprehensive because it contains a much larger dataset that compares experienced examiners to inexperienced examiners. However, unlike the Lemley and Sampat study, this study focuses only on experienced examiners to determine the variations between low volume and high volume examiners. Additionally, unlike the Lemley and Sampat study, this study not only focuses on the examiner Office Actions, but also surveys the applicant responses to determine how the interplay between examiner and applicant can cause delayed allowance. Furthermore, this study actually goes into the prosecution history for each patent reviewed and looks: (1) to the type of prior art rejection used, (2) the prior art that the rejection was based on, and (3) the applicant's traversal strategies to those rejections.

Frakes and Wasserman also study examiner behavior by comparing examiners with differing levels of experience. ${ }^{41}$ Their study suggests that as an examiner with more experience "is given less time to

38 For workgroup 1610 - i.e., the workgroup analyzed in this study - the average allowance rate is approximately twenty-five patents per year.

39 See Lemley \& Sampat, supra note 3.

40 See id. at 822-26.

41 See Frakes \& Wasserman, supra note 1. 
review an application, the less active [they] become[] in searching for prior art, ... and the more likely [they] become[] to grant the patent." ${ }^{42}$ Specifically, Frakes and Wasserman find that "[a]s examination time is cut roughly in half, ... grant rates [can] rise by as much as [ten] to [nineteen] percentage points, or by roughly [fifteen] to [twenty-eight percent]. ${ }^{243}$ Interestingly, they show that there is a decrease in the number of obviousness rejections, as well as the share of prior art citations found by examiners when moving to a higher GS level ${ }^{44}$ Accordingly, they argue that patents that are granted under a shorter review time are of "weaker-than-average quality." 45

The reasonable assumption underlying this "weaker-thanaverage quality" hypothesis is that patents that can overcome one or more obviousness rejection(s) are stronger than patents that encountered fewer or no obviousness rejections. However, this statement cannot be justified without a detailed review of both the claims and an analysis of the rejections proffered by the examiner. It could be that examiners who spend more time writing multiple obviousness rejections are doing so because of a misunderstanding of either the art or the invention, thus increasing the number of bogus obviousness rejections. Alternatively, a high number of obviousness rejections during prosecution might simply be a function of a count maximization strategy based on high rejection rates. The instant study attempts to address this issue by reviewing both the rejections and traversal responses, as well as the claims that are issued after issuance by differing types of examiners.

Finally, in a recent empirical study, Stephen Yelderman reviewed the district courts' reliance on prior art to invalidate patents. ${ }^{46}$ Yelderman found that "[a]nticipation based on obscure prior art ... [is] quite rare." 47 In contrast, the study found that patents invalidated by obviousness rely on prior art that would have been difficult or impossible to find at the time of invention. ${ }^{48}$ Yelderman's study suggests that examiners should focus more on the searching for relevant prior art references when making an obviousness rejection, while relying more on the cited art (or inventor's own prior work) when making an anticipation rejection.

$42 \mathrm{Id}$. at 550 .

$43 \mathrm{Id}$. at 551

44 See $i d$. at 559. The number of spendable hours allotted to an examiner on an application correlates with the general GS pay scale. Id. at 558-60, $558 \mathrm{tbl} .3$.

$45 \mathrm{Id}$. at 560 .

46 See Yelderman, supra note 2, at 837.

47 Id. at $837,882-83$.

48 Id. at $883-86$. 


\section{THE DATASET}

As an initial matter, this dataset focuses only on primary examiners from workgroup 1610. This workgroup was chosen because the author has a background in pharmacology, and has prosecuted many patent applications in this workgroup. ${ }^{49}$ Accordingly, there is an element selection bias with this dataset due to the unique issues present in biotechnology patents. Because the author was the sole coder for the dataset, there is consistency in both coding and expertise.

Secondary (junior) examiners-meaning examiners who lack signatory authority-were excluded because their lack of experience could confound the data. Additionally, junior examiners have a "ramp up" stage where they do not allow patents early on in their career simply because they have a docket of cases that are usually in the initial or early stage of patent prosecution. Accordingly, only primary examiners with at least eight years of experience were included in the dataset.

Previous studies have determined that there are three distinct groups of examiners: (1) examiners who grant patents at a high volume, at a rate of more than fifty patents per year ("fast examiners"); (2) examiners who grant patents at a rate consistent with other patents in their art unit ("average examiners"); and (3) examiners who grant patents at a low volume, at a rate of less than five patents per year ("slow examiners") ${ }^{50}$ Unlike previous studies that focus only on the procedural aspects of issued patents, this study reviews the substantive rejections and responses by both patent examiners and the applicant. Specifically, this study reviews one hundred patents in each of the three specified categories of examiners - i.e., fast examiners, average examiners, and slow examiners - and takes into account the prosecution histories of these patents.

Specifically, from these three groups (fast, average, and slow examiners), ten examiners were randomly chosen from each group, and then ten patents from each of those examiners were randomly chosen. Thus, each group contained one hundred randomly chosen patents from the ten randomly chosen examiners. Accordingly, the complete dataset contained three hundred patents from thirty different examiners. The patent prosecution histories were then reviewed, and prior art rejections and traversal responses were coded.

49 The author's pertinent credentials are as follows: B.S. in Microbiology and B.S. in Chemistry, University of Florida (1997); Ph.D. in Pharmacology, Cornell University (2003); Associate with Foley \& Lardner (Chemical, Biotechnology \& Pharmaceutical Practice/Life Science and Nanotechnology Industry Team).

50 See Tu, Luck/Unluck of the Draw, supra note 1, at 14. 


\section{A. Examiner Rejection Metrics}

In order to conduct the study, basic application information was recorded, such as the application filing date and the issue date, to determine the number of days the application was in prosecution. Then priority documents associated with each individual patent were recorded, if present. Specifically, it was first determined whether there was a provisional application associated with the patent. Additionally, it was determined whether there was a priority application that was associated with either a foreign filing or a U.S. parent application. If there was an associated U.S. parent, it was determined whether the same examiner had reviewed the parent application. ${ }^{51}$ This was done to determine whether either slow or fast examiners had a higher proportion of applications within a larger family, and whether that same examiner had reviewed applications from that larger family.

Rejections based on 35 U.S.C. $\S \S 102$ and 103 were then documented. All prosecution histories reviewed were from pre-AIA applications. ${ }^{52}$ Specifically, rejections were recorded based on Section 102(a), (b), and (e) prior art. ${ }^{53}$ The same type of analysis was done for Section 103 rejections. For each prior art rejection, it was determined what type of prior art was used: (1) U.S. patent, (2) U.S. patent application, (3) foreign patent, (4) foreign patent application, or (5) printed publication. Finally, the total number of unique references used was captured for all Section 102 and 103 rejections. ${ }^{54}$ These data attempt to determine how many total references were used during prosecution to get an idea of the breadth and scope of the examiner's search.

\section{B. Applicant Response Metrics}

Similar to the examiner side, a review was conducted of every response filed by the applicants to every non-final and final Office

51 See infra Appendices A1, A2, B1, B2.

52 Accordingly, all 35 U.S.C. $\S 102$ and $\S 103$ rejections were from pre-AIA applications (before March 16, 2013).

53 See Patent Act, 35 U.S.C. $\$ 102$ (2011), https://www.govinfo.gov/content/pkg/USCODE-2011title35/pdf/USCODE-2011-title35-partII-chap10-sec 102.pdf [https://perma.cc/8YCJ-2KTL]. No other Section 102 rejection were found in this dataset. Accordingly, there were no rejections based on Sections 102(c), (d), (f), or (g). See id. Additionally, there were no Section 102 rejections based on the "on sale" or "public use." See Patent Act, 35 U.S.C. \& 102(a)(1) (2018), https:// www govinfo. gov/content/pkg/USCODE-2018-title35/pdf/USCODE-2018-title35-partII-chap 10sec102.pdf [https://perma.cc/94F7-67FA].

54 "Unique references" are especially important for rejections based on obviousness under Section 103. See 35 U.S.C. $\S 103$, https://www.govinfo.gov/content/pkg/USCODE-2018-title35/pdf/ USCODE-2018-title35-partII-chap10-sec103 pdf [https://perma.cc/8YXL-T9UZ]. For example, if the examiner rejected claim one based on References $\mathrm{A}$ and $\mathrm{B}$, and also rejected claim one based on References $A$ and $C$, the study would only account for three references, not four. Furthermore, if the examiner used the same reference in any subsequent rejections, then that reference was not counted again 
Action. For each rejection, there was an effort to characterize the type of argument used to traverse the prior art rejection.

For Section 102 (a), (g), or (e) anticipation rejections based on prior art, ${ }^{55}$ the study coded for traversal strategies based on: (1) claim amendments, (2) missing element argument(s), (3) no motivation to modify argument(s), (4) prior art reference was not enabled argument(s), (5) reference is not prior art using a 131 declaration, ${ }^{56}$ or (6) "other" argument(s). ${ }^{57}$ Additionally, the study recorded the number of times a 132 declaration ${ }^{58}$ was used in conjunction with the applicant's arguments. For Section 102(b) anticipation rejections based on prior art, the study coded for traversal strategies based on: (1) claim amendments, (2) missing element argument(s), (3) no motivation to modify, or (4) "other" argument(s). ${ }^{59}$ Similar to the approach to Section $102(\mathrm{a}),(\mathrm{g})$, or (e), the study also recorded the number of times a 132 declaration was submitted to traverse the rejection ${ }^{60}$ in conjunction with the applicant's arguments.

Finally, for Section 103 obviousness type rejections based on prior art, the study coded for traversal strategies based on: (1) claim amendments, (2) missing element argument(s), (3) no motivation to modify argument(s), (4) no motivation to combine argument(s), (5) reference is not prior art using a 131 declaration, (6) prior art reference is not enabled argument(s), (7) reference teaches away from invention argument(s), (8) unexpected results argument(s), (9) not obvious to try argument(s), (10) no expectation of success argument(s), and (11) "other" argument(s). ${ }^{61}$ Additionally, it recorded the number of times a 132 declaration was submitted to traverse the rejection in conjunction with the applicant's arguments. ${ }^{62}$

\section{RESULTS}

As an initial matter, the difference in prosecution times for each group of examiners was significant. While fast examiners, on average, issued patents 620 days ( 1.7 years) after the application date, average

\footnotetext{
55 These include rejections based on Section 102(a), (g), (e), and (b). No other Section 102 prior art rejections were found in this dataset.

56 See 37 C.F.R. $\S 1.131$ (a) (2019), https://www.govinfo.gov/content/pkg/CFR-2019-title37-vol1/ $\mathrm{pdf} / \mathrm{CFR}-2019-$ title37-vol1-sec 1-131.pdf [https://perma.cc/C3KX-5GZQ].

57 The "other' argument(s)" category was used as a catch-all if the argument used in prosecution did not squarely fit in a previously mentioned category.

58 See 37 C.F.R. $\$ 1.132$, https://www govinfo.gov/content/pkg/CFR-2019-title37-voll/pdf/CFR2019-title37-vol1-sec1-132.pdf [https://perma.cc/4UZX-2H9J]; see also MPEP, supra note 13, § 716.

59 The "other' arguments" category acted as a catch-all for those arguments used during prosecution that did not squarely fit into one of the three preceding categories.

60 See 37 C.F.R. $\S 1.132$; see also MPEP, supra note 13 , § 716.

61 The "other' arguments" category acted as a catch-all for those arguments used during prosecution that did not squarely fit into one of the ten preceding categories.

62 See 37 C.F.R. § 1.132; see also MPEP, supra note $13, \S 716$.
} 
examiners issued patents 1,121 days (3.07 years) after the application date, and slow examiners issued patents 2,138 days ( 5.86 years) after the application date. Thus, fast examiners are almost twice as fast as average examiners, and more than three times as fast as slow examiners.

\section{A. Statistical Analysis}

In each section, graphs will be used to summarize the data along with their corresponding statistical analysis. Additionally, some graphs will contain a separate table showing which group of examiners are statistically different from other groups. These tables contain the letters $A, B$, or $C$. The letter $A$ denotes that the group of examiners has the largest frequency of that particular metric. The letter $B$ denotes the second largest frequency and is significantly different from $A$ and $C$. The letter $C$ denotes the smallest frequency and is significantly smaller than $A$ or $B$. Several groups may contain the same letter, which connotates that there is no significant difference between those groups. The designation of $A / B$ means that the group is not statistically different from either $A$ or $B$.

The Kruskal-Wallis test is used to test whether a variable is different among the three examiner groups. ${ }^{63}$ The "Level-Level" columns indicate the order of subtraction, and the $p$-values show significance. The "SMD" column represents the "Score Mean Difference," which is calculated from the ranks of the numbers from the whole dataset. The formula for SMD is SMD = \{Sum of group l scores -0.5$\} / n l-\{$ Sum of group 2 scores $+0.5 \xi / n 2$. A positive SMD represents that the first group has larger scores than the second, while a negative SMD represents that the second group has larger scores. A p-value that is less than five percent shows that the difference is significant.

The pair-by-pair Kruskal-Wallis test is generally used for considering the ranks of the numbers within any pair of examiner groups and may cause problems for a test of more than two groups. This study therefore used Dunn's test as well, because the Dunn's test considers all the groups as a whole when finding ranks of the numbers. ${ }^{64}$

Additionally, the Kruskal-Wallis test was used to test whether there is significant difference in a certain variable among the three examiner groups. ${ }^{65}$ The chi-squared test and p-value show how the examiners are different regarding a certain variable. For each variable,

63 William H. Kruskal \& W. Allen Wallis, Use of Ranks in One-Criterion Variance Analysis, $47 \mathrm{~J}$. AM. STAT, ASS'N 583 (1952), http://webspace.ship.edu/pgmarr/Geo441/Readings/Kruskal\%20and $\% 20$ Wallis $\% 201952 \% 20-\% 20$ Use $\% 20$ of $\% 20$ Ranks $\% 20$ in $\% 20$ One-Criterion $\% 20$ Variance $\% 20$ Analysis.pdf [https://perma.cc/QHH7-8AYP]

64 Olive Jean Dunn, Multiple Comparisons Among Means, 56 J. AM. STAT. ASS'N 52 (1961), https://sci2s.ugr.es/keel/pdf/algorithm/articulo/1961-Bonferroni_Dunn-JASA.pdf [https://perma. cc/VC43-UCAA]

65 Kruskal \& Wallis, supra note 63. 
the variables are grouped (as indicated by letters) by whether they are different from each other. While same letters represent same groups, the letter $A$ represents a higher score than the letter $B$, and the letter $B$ represents a higher score than the letter $C$.

\section{B. General Prosecution History Statistics}

\section{Priority Documents Metrics}

As an initial matter, this study determined whether any group of examiners (slow, average, or fast) had a disproportionate amount of priority applications. Specifically, it determined whether the patent examined had a priority to a provisional application, continuation application, continuation in part application, divisional application, or foreign priority document. ${ }^{66}$ This determination is important because an examiner may have previously reviewed a family member of the current application. If the examiner had previously reviewed a parent or related application, it would allow the examiner to review the current application more quickly. This is because the examiner is likely to be more familiar with the technology, as well as the prior art from the previous priority document and a prior review of the related specification.

First, these data show that average examiners have a slightly higher number of priority documents compared to either the fast or the slow examiners. ${ }^{67}$ In contrast, fast examiners do not have a significantly higher number of patents that claim priority when compared to slow examiners. Interestingly, all examiners (slow, average, and fast) receive approximately the same number of applications that claim priority to a provisional application. ${ }^{68}$ However, the slow examiners have a significantly smaller number of applications that they had previously reviewed as a related family member ${ }^{69}$ Average and fast examiners did not have a significant difference in the number of previously examined related applications.

\section{Length of Office Actions and Responses}

In order to capture the detail present in each Office Action, the number of pages was used as a proxy for the verbosity of the examiner's Office Action. The study determined that slow examiners give a larger number of rejections per Office Action and so, unsurprisingly, slow examiners have much longer Office Actions. Slow examiners have significantly longer Office Actions than their average or fast counterparts

66 See infra Appendices A1, A2

67 See infra Appendices A1, A2.

68 See infra Appendices B1, B2.

69 See infra Appendices B1, B2. 
(total pages/number of Office Actions +1$).^{70}$ For the "total pages" analysis, the denominator includes the number of Office Actions plus one. The added value of "plus one" in the denominator was included to capture those examiners who allow a case with a first action allowance. This is true for both non-final Office Actions (NFOAs), as well as final Office Actions (FOAs).

The study found that average Office Action length for slow examiners (6.4 pages) is almost twice the length as that of fast examiners (3.6 pages). Slow examiners write significantly longer non-final Office Actions (11.6 pages) than average examiners (9.2 pages) or fast examiners (8.6). Interestingly, this gap increases dramatically when it comes to final Office Actions (12.3 pages compared to 8.9 and 6.1 pages). Thus, slow examiners are writing longer non-final Office Actions and much longer final Office Actions as compared to their average and fast counterparts.

\section{Examiner Rejection Statistics Based on 35 U.S.C. $\S \S 102$ and 103-Anticipation and Obviousness Based on Prior Art}

First, this study determined if examiners were using different types of rejections based on their classification as slow, average, or fast examiners. It focused only on prior art rejections based on Section 102(a), (g), or (e) (prior art only), Section 102(b) (prior art only), and Section 103 (prior art) ${ }^{71}$ It then looked at the associated applicant responses. ${ }^{72}$

Unsurprisingly, both slow and average examiners tend to give many more Section 102 and 103 rejections as compared to their fast counterparts. These data extend what was previously shown with junior and senior examiners. ${ }^{73}$ Similar to previous studies, which show that junior examiners are more likely to use prior art rejections as compared to their senior counterparts, this study shows that both average and slow examiners use more prior art rejections as compared to their fast counterparts.

Prior art rejections tend to be the most time-consuming rejections for examiners because they require a detailed search, as well as a substantive comparison between the prior art and the claimed invention. A comprehensive prior art search requires the examiner to not only understand the claimed invention, but also where it sits within the larger

70 See infra Appendices C1, C2.

71 A separate study, not addressed in this Article, will examine the role of rejections based on statutory type double patenting, obviousness-type double patenting, utility, and patentable subject matter under Section 101, and rejections based first on written description and enablement, and second on indefiniteness under Section 112

72 See discussion supra Section III.B.

73 See Lemley \& Sampat, supra note 3, at 821-22, 821 tbl.3; see also Frakes \& Wasserman, supra note 1 
technological environment. Additionally, a well-written prior art rejection requires the examiner to understand the prior art and how it is similar to and different from the claimed invention. Furthermore, an appropriate prior art rejection will require the applicant to either amend the claim or abandon the application. Finally, prior art rejections are the most common method by which patents are invalidated during litigation. ${ }^{74}$ Accordingly, examiners may spend a disproportionate amount of their allotted examination time searching, reviewing, comparing, and composing a prior art rejection.

Figure 2 and Table 1 show the relative number of prior art rejections found per Office Action for slow, average, and fast examiners. ${ }^{75}$ Slow examiners have almost five times as many Section 102(a), (g), or (e) rejections, almost two times as many Section 102(b) rejections, and almost six time as many Section 103(a) rejections as compared to their fast counterparts. Accordingly, these data show that slow examiners give (statistically significant) more prior art rejections as compared to fast examiners.

Interestingly, this result is not identical when comparing slow examiners with average examiners. Specifically, slow examiners and average examiners generate approximately the same number of anticipation rejections (Section 102 rejections). However, slow examiners give approximately 1.5 times as many obviousness rejections as compared to their average counterparts.

Figure 2 .

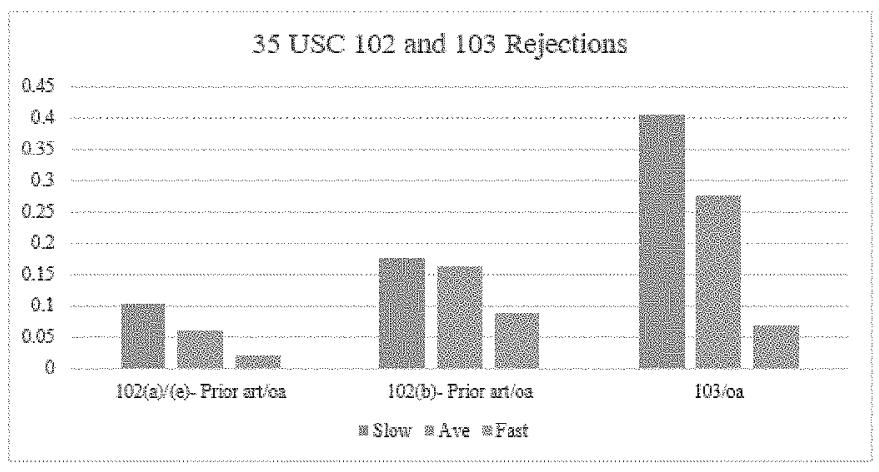

74 See Shine Tu, Invalidated Patents and Associated Patent Examiners, 18 VAND. J. ENT. \& TECH. L. 135,160 (2015), http://www.jetlaw.org/wp-content/uploads/2016/01/Tu_SPE_6-FINAL.pdf [https://perma.cc/2FTW-HRV5]. However, many patents that are invalidated based on Section 102 or Section 103 prior art are not initially discovered by the examiner during patent prosecution. Instead, most invalidated patents based on prior art are typically discovered by third parties after patent prosecution.

75 See infra Figure 2; see also infra Table 1. 
Table 1.

\begin{tabular}{|c|c|c|c|c|c|c|}
\hline \multirow{2}{*}{ Rejection/OA } & \multicolumn{2}{|c|}{ Fast-Ave } & \multicolumn{2}{|c|}{ Are-Slow } & \multicolumn{2}{|c|}{ Fast-Slow } \\
\hline & SWD & p-rallue & SMD & p-value & SMD & $\mathrm{p}$-value \\
\hline $102(a) /(\mathrm{g}) /(\mathrm{e})$-Priar art & -163290 & 0.1117 & -158416 & 01283 & -32184 & sho \\
\hline 102(b)-Prier art & 2495 & Dorgs & -12.7475 & 0.6302 & 372738 & 0.000 \\
\hline 103 & 373 & 06001 & 32.190 & 9023 & 89507 & $\infty 0,000$ \\
\hline \multirow{2}{*}{ Rejection reasons/OA } & \multirow{2}{*}{$x^{3}$} & \multirow{2}{*}{ p-yalue } & \multicolumn{3}{|c|}{ Groups } & \\
\hline & & & Slow & Ave & Fast & \\
\hline $102(\mathrm{a}) / \mathrm{g})(\mathrm{e})$-Pror art & 168636 & 0.0002 & A & $\mathrm{AB}$ & $B$ & \\
\hline 102(b)-Prior art & 13.8091 & 00010 & A & A & B & \\
\hline 103 & 65.1099 & 80.0001 & A & B & $\mathrm{C}$ & \\
\hline
\end{tabular}

\section{Applicant Responses to 35 U.S.C. $\S 102$-Anticipation Rejections Based on Prior Art}

Although slow and average examiners may be producing approximately the same number of anticipation rejections, these data alone cannot determine the quality of these rejections. Similarly, these data alone cannot determine if the relatively few anticipation and obviousness rejections generated by fast examiners are valid. Specifically, by looking only at the examiner's rejections, it is difficult to tell if these prior art rejections are strong or weak. Accordingly, the applicant responses are necessary to help determine the validity of these rejections.

The methods by which applicants respond to the examiner's prior art rejection can help reveal the strength of the rejection. Specifically, if a claim amendment is the sole argument used to traverse the rejection, it may signal that the prior art rejection was a strong rejection. ${ }^{76}$ Conversely, if a missing elements argument is the sole method used to traverse the prior art rejection, it may signal that the prior art rejection was a weak rejection because the examiner misunderstood either the prior art or the claimed invention. This study uses the applicant responses as a proxy to help determine the strength or weakness of the examiner's prior art rejection.

1. Applicant Responses to 35 U.S.C. § 102(a), (g), or (e)Anticipation Rejections Based on Prior Art

As an initial matter, the study recorded each type of reference used in the Section 102(a), $(\mathrm{g})$, or (e) rejections. ${ }^{77}$ These data show that

76 It is understood, however, that there are many reasons an applicant may only use a claim amendment to traverse a prior art rejection that has nothing to do with the strength of the rejection. These reasons include speeding up prosecution or avoiding the attorneys' fees required to create a strong rebuttal. See Douglas Lichtman, Rethinking Prosecution History Estoppel, 71 U. CHI. L. REV. 151, 153 (2004), https://chicagounbound.uchicago.edu/cgi/viewcontent.cgi?article $=5250$ \& context=uclrev [https://perma.cc/UE3J-65Q6] ("[T]he patent holder bears the burden of establishing the reason for any narrowing amendment, and, where no explanation can be established, courts are to presume that estoppel applies."); see also Warner-Jenkinson Co., Inc. v. Hilton Davis Chem. Co., 520 U.S. 17 (1997).

77 See infra Appendix D. Notably, the study averages the number of references over all Office Actions in the prosecution history. Because not every Office Action will have an anticipation 
U.S. patents are the most frequently used source of 102(a), (g), or (e) prior art. Additionally, slow examiners use almost nine times as many references per Office Action as compared to a fast examiner and over 1.5 times as many references per Office Action as compared to an average examiner.

The methods by which applicants responded to the examiner's Section 102(a), (g), or (e) rejections were also different depending on which examiner type made the rejection. As shown in Figure 3 and Table 2 , claim amendments are the most common way applicants traverse prior art rejections based on Section 102(a), (g), or (e) prior art. ${ }^{78}$ However, Figure 3 and Table 2 demonstrate that many more applicants responded to slow examiners by arguing that the prior art had a missing element when compared to the claimed invention. ${ }^{79}$ Additionally, with slow examiners, many applicants used a 131 declaration to antedate the prior art. Overall, applicants would much less frequently use a 132 declaration to try to overcome a Section 102(a), (g), or (e) prior art rejection regardless of which type of examiner they encountered.

An anticipation rejection under 35 U.S.C. $\S 102(\mathrm{a}),(\mathrm{g})$, or (e) requires that each and every element of the claimed invention be disclosed in a single prior art reference. ${ }^{80}$ Applicants who argue against this type of rejection based on a "missing elements"-type response are basically arguing that the prior art reference lacks at least one element in the claimed invention. The argument relies on the fact that the examiner has either misunderstood the claimed invention or the prior art reference. It is notable that some applicants make a claim amendment in conjunction with an argument that the modified claim now adds an element that is missing in the prior art reference. If an applicant made both a claim amendment and a missing element argument based on that new claim amendment, then the data was recorded only as a "claim amendment" and not as a "missing element" argument. This is because if a claim amendment adds an element, then the examiner may have correctly interpreted both the claimed invention and the prior art reference.

Importantly, slow examiners encounter the missing elements argument more than other examiners. Furthermore, it is the most common argument made by applicants against Section 102(a), (g), or (e) rejections from slow examiners. Figure 3 and Table 2 show that slow examiners receive about three times as many missing element arguments as compared to their fast or average examiner counterparts. ${ }^{81}$ Thus, slow

rejection, there can be less than one reference per Office Action when averaged over all Office Actions in the application's prosecution history

78 See infra Figure 3; see also infra Table 2.

79 See infra Figure 3; see also infra Table 2.

80 See Patent Act, 35 U.S.C. 102 (2018); see also MPEP, supra note 13, 2131.

81 See infra Figure 3 ; see also infra Table 2. 
examiners may be either misinterpreting the prior art or the claimed invention at a much higher rate than their average or fast examiner counterparts. Interestingly, applicants rarely must make claim amendments to overcome an anticipation rejection when dealing with a fast examiner. In contrast, claim amendments are over four times more likely to occur to overcome an anticipation rejection when dealing with a slow or average examiner.

Figure 3.

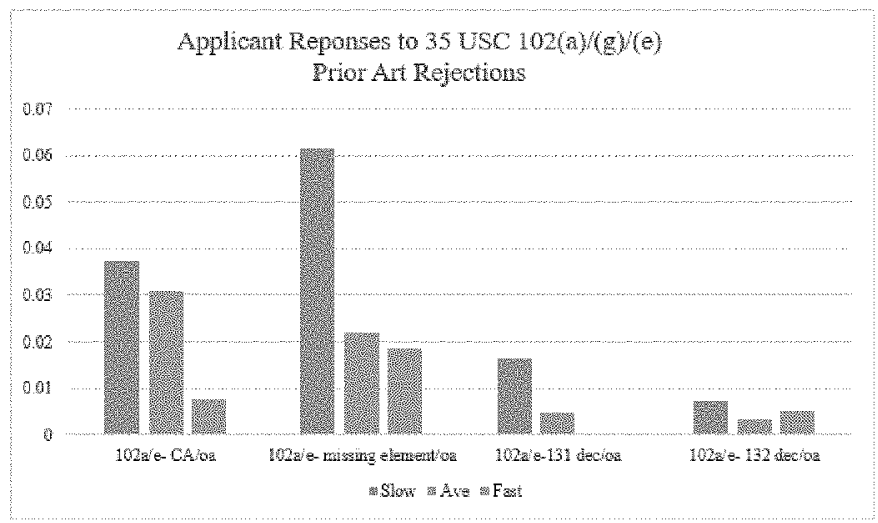

Table 2 .

\begin{tabular}{|c|c|c|c|c|c|c|}
\hline \multirow{2}{*}{ Rejection/OA } & \multicolumn{2}{|c|}{ Fast-Ave } & \multicolumn{2}{|c|}{ Ave-Slow } & \multicolumn{2}{|c|}{ Fast-Slow } \\
\hline & SMD & p-value & SMD & $p$-value & SMD & p-value \\
\hline $1023 / \mathbf{e}-\mathrm{CA}$ & -10.4744 & 0.2095 & -5.6931 & 0.9697 & $-1617 \%$ & 804 \\
\hline $102 \mathrm{a} / \mathrm{e}-$ Missing elements & -5.4368 & 10000 & -14.8713 & 0.0591 & 20380 & 0004 \\
\hline 102a/e-131 declaration & -1.49500 & 1.0000 & -595050 & 0.1354 & 74554 & 00365 \\
\hline 102a/e 132 declaration & 0.02000 & 1.0000 & -296535 & 0.8247 & -293535 & 0.8430 \\
\hline \multirow{2}{*}{ Rejection reascas/OA } & \multirow{2}{*}{$x^{2}$} & \multirow{2}{*}{ p-value } & \multicolumn{3}{|c|}{ Groups } & \\
\hline & & & Slow & Are & Fiast & \\
\hline $102 \mathrm{a} / \mathrm{e}-\mathrm{CA}$ & 80714 & 0.0177 & A & Ad & B & \\
\hline 102a/e-Missing elements & 108528 & 0.9044 & A & $\mathrm{A} / \mathrm{B}$ & B & \\
\hline $102 \mathrm{a} / \mathrm{e}-131$ declaration & 70469 & 00295 & A & AB & B & \\
\hline 102a/e-132 declaration & 15816 & 04535 & A & A. & $A$ & \\
\hline
\end{tabular}

2. Applicant Responses to 35 U.S.C. § 102(b) - Anticipation Rejections (Statutory Bar) Based on Prior Art

Similar to Section 102(a), (g), or (e) rejections, applicants traverse Section 102(b) rejections mainly based on claim amendments or missing elements arguments. Interestingly, unlike with Section 102(a), $(\mathrm{g})$, or (e) rejections, applicants increase their use of missing element(s) arguments against average examiners. This may reflect the more difficult nature of overcoming Section 102(b) rejections compared to Section 102(a), (g), or (e) rejections, because one cannot antedate a Section 102 (b) rejection with a 131 declaration. Additionally, many of the Section 102 (b) rejections were based on the applicant's own prior art, which is unavailable under Section 102(a), (g), or (e). 
In addition, Figure 4 and Table 3 show that claim amendments and the missing elements arguments are the most frequent ways applicants traverse Section 102(b) rejections. ${ }^{82}$ Like the novelty rejections based on Section 102(a), (g), or (e), slow examiners force applicants to make claim amendments nearly twice as frequently as fast examiners. Additionally, the missing elements argument occurs more than twice as frequently with slow examiners as compared to fast examiners. Accordingly, one interpretation of these data is that slow examiners misunderstand either the prior art or the claimed invention at a much higher rate than fast examiners.

Interestingly, all examiners who use Section 102(b) rejections are mainly using printed publications as prior art ${ }^{83}$ However, examiners are still also using U.S. patents to a large degree. Unsurprisingly, average and slow examiners use approximately 1.5 more U.S. patent references per Office Action than their fast examiner counterparts. Surprisingly, fast, average, and slow examiners all use approximately the same number of printed publications per Office Action when making a Section 102(b) rejection. These data suggest that when searching for Section 102(b) prior art, all examiners most likely use outside searches that focus on nonpatent literature.

Figure 4.

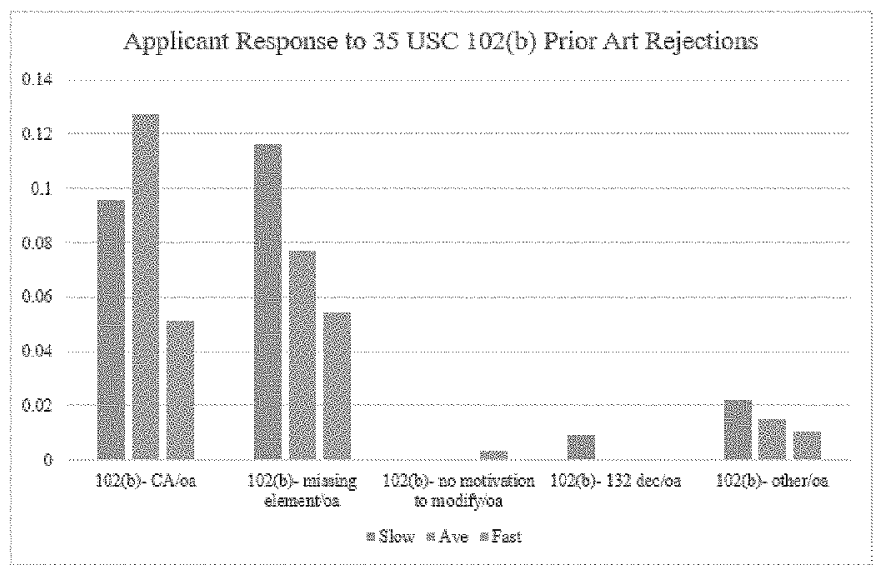

82 See infra Figure 4; see also infra Table 3.

83 See infra Appendix E (outlining the total number of references, as well as the type of references being used by each examiner). Notably, the study averages the number of references over all Office Actions in the prosecution history. Because not every Office Action will have an anticipation rejection, there can be less than one reference per Office Action when averaged over all Office Actions in the application's prosecution history. 
Table 3 .

\begin{tabular}{|c|c|c|c|c|c|c|}
\hline \multirow{2}{*}{ Rejection reasous $/ O A$} & \multirow{2}{*}{$x^{2}$} & \multirow{2}{*}{ p-xalue } & \multicolumn{3}{|c|}{ Groups } & \\
\hline & & & Siow & Awe & Fast & \\
\hline $102(b)-C A$ & 138975 & 0.0010 & A & A & $\mathrm{B}$ & \\
\hline 102(b) -Missing elements & 10.4754 & 0.0053 & A & $A D$ & $\mathrm{~B}$ & \\
\hline $\begin{array}{l}\text { 102(b)-Ma motivation to } \\
\text { modify }\end{array}$ & 2.0200 & 0.3642 & A & $\mathrm{A}$ & $\mathrm{A}$ & \\
\hline $102(b)-132$ declaration & 60101 & 0.0495 & A & $A$ & $A$ & \\
\hline $102(b)$-other & 3.5449 & 0.1699 & A & A & A & \\
\hline \multirow{2}{*}{ Rejection/OA } & \multicolumn{2}{|c|}{ Fast-Ave } & \multicolumn{2}{|c|}{ Ave-Slow } & \multicolumn{2}{|c|}{ Fase-Slow } \\
\hline & SMD & p-value & SMD & p-value & SMD & $p$-valua \\
\hline $102(b)-\mathrm{CA}$ & $.204 \% 6$ & WhW & -1.1485 & 10000 & पदिध & 10000 \\
\hline $102(b)$-Missiug elements & -13.1377 & 0.406 & -15.2871 & 0.2446 & $28 \sqrt{3} 3$ & 0003 ? \\
\hline $\begin{array}{l}\text { 102(b)-nen motivation to } \\
\text { modify }\end{array}$ & 1.500050 & 0.6631 & 0.000000 & 1.0000 & 1.500050 & 0.6631 \\
\hline 102(b)-132 declaration & 0.00000 & 1.0000 & -4.47525 & 0.1020 & -4.47520 & 0.1033 \\
\hline $102(6)$-other & -4.32540 & 1.0000 & -4.38614 & 1.0000 & -8.72144 & 0.1801 \\
\hline
\end{tabular}

\section{E. Applicant Responses to 35 U.S.C. $\S 103$-Anticipation Rejections Based on Prior Art}

35 U.S.C. $\S 103$ obviousness rejections are one of the most important and common means by which examiners reject applications and litigators invalidate patents. ${ }^{84}$ Because obviousness rejections usually rely on a combination of references to achieve each and every element of the claimed invention, the strategies used by applicants to traverse this type of rejection are broader than with other types of rejections. Figures 5 and 6 , as well as corresponding Tables 4 and 5, outline the different traversal strategies typically used to overcome Section 103 rejections. ${ }^{85}$ Many of the patents reviewed were patents with pre-KSR Int'l Co. $v$. Teleflex Inc. ${ }^{86}$ application dates that were issued post-KSR. This is important because $K S R$ greatly blunted the motivation to combine arguments, although some commentators argue there is a growing resurgence of this type of argument. ${ }^{87}$

\section{35 U.S.C. $§ 103$ - Claim Amendment Traversal Argument}

As presented in Figure 5 and Table 4, a common way an applicant addresses an obviousness rejection is to make claim amendments. ${ }^{88}$ This strategy is similar to that seen in the anticipation context. That is, applicants will change one or more elements of the claim to address the issues that concern the examiner. In the anticipation context, this usually

$84 \mathrm{Tu}$, supra note 74 , at 151 . However, many of the patents invalidated by either Section 102 or Section 103 prior art are not initially discovered by the patent examiner during prosecution. Instead, most invalidated patents based on prior art are discovered by third parties after patent prosecution. 85 See infra Figures 5, 6; see also infra Tables 4, 5.

86 See KSR Int'l Co. v. Teleflex Inc., 550 U.S. 398 (2007).

87 See Chao Gao \& Peter M. Jay, Ten Years after KSR, Motivation to Combine Moves Back into the Spotlight, 10 LANDSLIDE 23 (2018); see also In re NuVasive, Inc., 842 F.3d 1376, 1381-85 (Fed. Cir. 2016) (holding that the PTAB needs to sufficiently explain why a person of ordinary skill in the art would have been motivated to combine the prior art teachings to arrive at the claimed invention).

88 See infra Figure 5; see also infra Table 4. 
means narrowing the claims to exclude the prior art or adding an element that is not present in one or more of the cited references.

Figure 5 and Table 4 reveal that claim amendments are used most frequently to overcome obviousness rejections from both slow and average examiners. ${ }^{89}$ However, claim amendments are rarely used when applicants encounter a fast examiner. Surprisingly, applicants are eleven times more likely to have to make a claim amendment when dealing with an obviousness rejection from a slow or average examiner as compared to a fast examiner. One interpretation of these data is that slow and average examiners correctly force applicants to narrow the scope of their claims in light of the prior art. However, when looking at all of the traversal strategies applicants use to overcome the obviousness rejection, a different pattern emerges.

\section{35 U.S.C. § 103-Missing Element(s) Traversal Argument}

Figure 5 and Table 4 establish that the most common response to an obviousness rejection from any type of examiner is a "missing elements" argument. ${ }^{90}$ The basis for this argument is identical in an obviousness context and an anticipation context. In both contexts, applicants argue that when each reference is combined, there is still one or more element(s) lacking. Because the reference(s) does not describe each and every element of the claimed invention, applicants argue that the rejection is improper.

However, there is a great disparity between the frequency of this argument among the three types of examiners. The missing element(s) argument is used mostly against slow examiners when compared to average or fast examiners. In fact, applicants use this argument over 4.5 times more frequently with slow examiners as compared to fast examiners and over 1.5 times more frequently with slow examiners as compared to average examiners. Similar to the anticipation arguments, one interpretation of these data is that slow examiners simply do not understand the prior art and/or the claimed invention.

\section{35 U.S.C. $\S 103-$ No Motivation to Combine Traversal Argument}

Because an obviousness rejection usually relies on two or more references, examiners typically give a reason why a person of ordinary skill in the art would combine the cited references to result in the claimed invention. ${ }^{91}$ One common traversal strategy is for the applicant to argue

89 See infra Figure 5; see also infra Table 4.

90 See infra Figure 5; see also infra Table 4.

91 See Ali Mojibi, An Empirical Study of the Effect of KSR v. Teleflex on the Federal Circuit's

Patent Validity Jurisprudence, 20 Alb. L.J. SCI. \& TECH. 559 (2010), http:// 
that a person of ordinary skill in the art would have no motivation to combine the references cited by the examiner. This argument is usually based on the fact that one or more references are not from the same field as the claimed invention, or that the reference is not reasonably pertinent to the particular problem with which the invention is involved. These types of arguments were coded as a "no motivation to combine" argument.

Appendix $\mathrm{F}$ shows that the problem is compounded by the fact that slow examiners are using approximately seven times as many references as fast examiners, and approximately 1.5 times as many references as average examiners. ${ }^{92}$ Notably, this study averaged the number of references over all Office Actions in the prosecution history. Because not every Office Action will have an obviousness rejection, there can be less than two references per Office Action when averaged over all Office Actions in the application's prosecution history.

Interestingly, Figure 5 and Table 4 show that slow examiners experience the "no motivation to combine" argument 30.5 times more frequently than fast examiners, and two times more frequently than an average examiner. ${ }^{93}$ Accordingly, slow examiners may be bringing in prior art that is too distant or non-relevant when making their obviousness rejections. Similar to the missing elements argument, this type of argument usually relies on the fact that the examiner has either misunderstood the claimed invention or misunderstood one or more of the prior art references.

Figure 5.

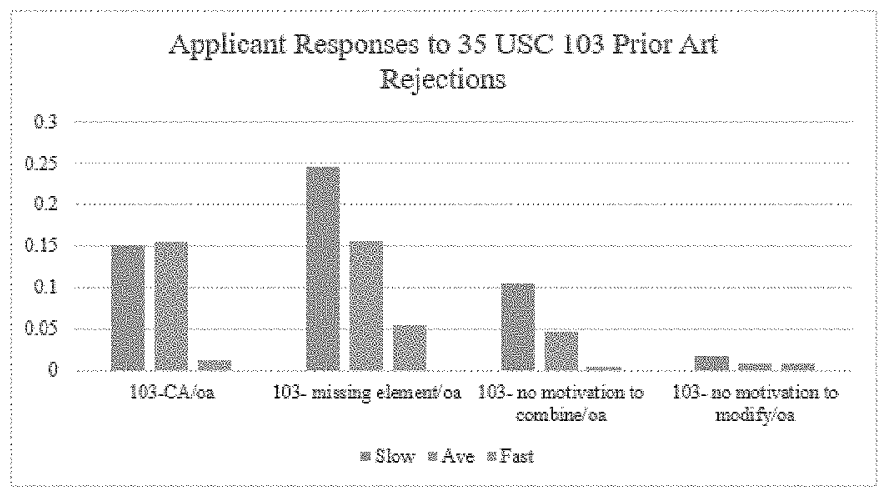

www. albanylawjournal.org/Documents/Articles/20.3.559-Mojibi.pdf [https://perma.cc/4J558WWRI; see also Gao \& Jay, supra note 87; see also Lee Petherbridge \& R. Polk Wagner, The Federal Circuit and Patentability: An Empirical Assessment of the Law of Obviousness, 85 TEX. L. REV. 2051 (2007), https://scholarship.law.upenn.edu/cgi/viewcontent.cgi?article=1098\& context =faculty_scholarship [https://perma.cc/26NG-266D]

92 See infra Appendix F (outlining the total number of references, as well as the type of references being used by each examiner).

93 See infra Figure 5; see also infra Table 4 
Table 4 .

\begin{tabular}{|c|c|c|c|c|c|c|}
\hline \multirow{2}{*}{ Rejection/OA } & \multicolumn{2}{|c|}{ Fast-Ave } & \multicolumn{2}{|c|}{ Ave-Slow } & \multicolumn{2}{|c|}{ Fast-Slow } \\
\hline & $\mathrm{SMD}$ & p-value & SWD & p-ralue & SIMD & p-value \\
\hline $103-C A$ & 58373 & 0000 & -10.6584 & 0.8551 & 65.9858 & $\infty 0001$ \\
\hline 103-Missing elements & 36456 & 00015 & -319624 & onom & 58.2179 & aloton \\
\hline $\begin{array}{l}\text { 103-uo motivation to } \\
\text { combine }\end{array}$ & -18.1876 & 0.0578 & $49+26$ & 01006 & nAOH & WuU⿴囗十 \\
\hline $\begin{array}{l}\text { Fu3-No motivation to } \\
\text { modify }\end{array}$ & 0.03525 & 1.0000 & -7.36139 & 0.1948 & -7.31614 & 0.2018 \\
\hline \multirow{2}{*}{ Rejectiun reasons/OA } & \multirow{2}{*}{$x^{2}$} & \multirow{2}{*}{ p-value } & \multicolumn{3}{|c|}{ Groups } & \\
\hline & & & Slow & Ave & Fast & \\
\hline $103-\mathrm{CA}$ & $50: 1798$ & 60.0091 & A & A & $\mathrm{B}$ & \\
\hline 103-Missing eleuents & 42.5954 & $=0.0091$ & $\mathrm{~A}$ & $\mathrm{~B}$ & $\mathrm{C}$ & \\
\hline $\begin{array}{l}\text { 103-ng metivation to } \\
\text { combine. }\end{array}$ & 37.9904 & 20.0001 & A & $B$ & $\mathrm{~B}$ & \\
\hline $\begin{array}{l}\text { 103-No motivation to } \\
\text { modify }\end{array}$ & 4.5196 & 0.1044 & $\mathbf{A}$ & $A$ & $A$ & \\
\hline
\end{tabular}

4. 35 U.S.C. $\$ 103$ - Use of 131 and 132 Declarations

Use of 131 and 132 declarations in an obviousness context is basically identical to use of these declarations in a Section 102(a), (g) or (e) context. Figure 6 and Table 5 outline how frequently applicants attempt to counter a Section 103 rejection using these declarations. ${ }^{94}$ Similar to the findings regarding applicant response rates to Section 102(a), (g), or (e) rejections, applicants more frequently use 131 declarations to overcome a Section 103 rejection from slow examiners when compared to their fast counterparts. Interestingly, 132 declarations are also much more frequently used by applicants who are working with slow examiners when compared with average or fast examiners. These 132 declarations are oftentimes expert testimony used to help the examiner interpret either the prior art or the claimed invention. ${ }^{95}$ Often, 132 declarations are used to refute an examiner's misunderstanding or misinterpretation of either the claimed invention or the prior art reference(s).

\section{35 U.S.C. $§ 103$-Teaching Away Traversal Strategy}

To successfully apply a teaching away argument, the applicant must show that the prior art reference would have actually motivated a person of skill in the art to move away from the claimed solution to the problem. ${ }^{96} \mathrm{~A}$ teaching away argument requires more than just a general preference for an alternative invention, but also requires the prior art to advocate abandoning or discouraging investigation in the claimed solution in the patent application. ${ }^{97}$ When an applicant is successful in making a teaching away argument, the examiner's prior art is usually relevant, but often shows the opposite result than the examiner intends.

94 See infra Figure 6; see also infra Table 5.

95 See MPEP, supra note $13, \S 716$.

96 See id. $\$ 2145$.

97 See Meiresonne v. Google, Inc., 849 F.3d 1379 (Fed. Cir. 2017). 
Accordingly, when successful, a teaching away argument is usually good evidence that the examiner has significantly misinterpreted the prior art.

Importantly, Figure 6 and Table 5 expose the fact that applicants who are paired with slow examiners much more frequently use a teaching away result or argument to overcome a Section 103 rejection. ${ }^{98}$ These arguments are important because both types of arguments usually rely on the examiner misunderstanding the technological field of the invention. Slow examiners experience a teaching away argument at rate of almost four times higher and more than fast examiners and more than 1.5 times more than average examiners. ${ }^{99}$ One interpretation of these data is that the examiner is utterly misunderstanding either the prior art reference or the claimed invention.

6. 35 U.S.C. $§ 103$ - Unexpected Results Traversal Strategy

When applicants use an unexpected results argument against an obviousness rejection, they usually argue that synergistic results or unexpected properties occur that make the claimed invention nonobvious. Unexpected results in an application can be based on a number of factors, including: (1) greater than or less than expected results, (2) the superiority of a property shared with the prior art, (3) the presence of an unexpected property, and/or (4) the absence of an expected property. ${ }^{100}$ Admittedly, these unexpected results may be difficult for an examiner to detect when reviewing the application. Synergistic results might not leap out of the specification, especially if the unexpected result is buried within a number of experiments described in the specification.

Slow examiners experience the unexpected results argument 3.5 times more frequently than fast examiners and almost two times more frequently than slow examiners. It may be that these examiners are not reviewing the specification closely when comparing the results of the claimed invention to the prior art references. Alternatively, it may be that slow examiners, in a rush to accumulate many prior art references, simply to do not closely review the results presented in the prior reference.

98 See infra Figure 6; see also infra Table 5.

99 See infra Figure 6; see also infra Table 5.

100 See MPEP, supra note $13, \S 716.02(\mathrm{a})$. 
Figure 6.

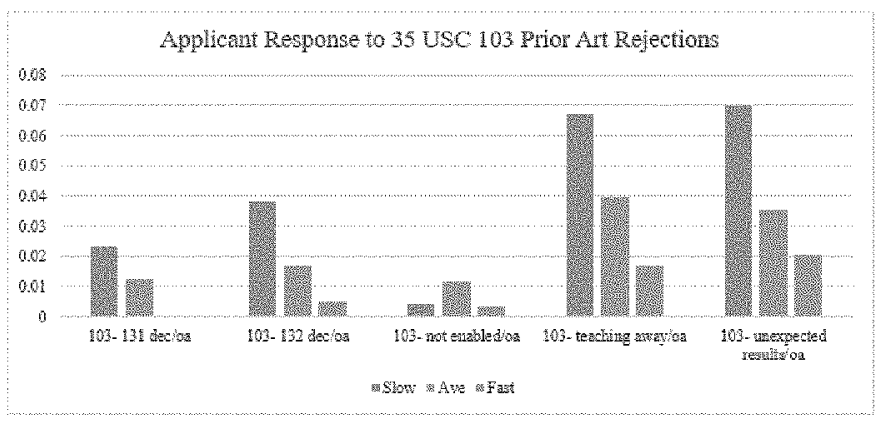

Table 5 .

\begin{tabular}{|c|c|c|c|c|c|c|}
\hline \multirow{2}{*}{ Rejection/OA } & \multicolumn{2}{|c|}{ Fast-Are } & \multicolumn{2}{|c|}{ Aye-Slow } & \multicolumn{2}{|c|}{ Fast-Slow } \\
\hline & SMD & p-watue & $\mathrm{SMD}$ & p-value & SMD & p-kalue \\
\hline 103-131 dedaration & -59851 & 0.453 & -5.9406 & 0.4594 & -11.9356 & 0,126 \\
\hline 103-132 declaration & -4.5485 & 1.0000 & 20452 & $B \mathrm{HOQ}$ & 230863 & 0000 \\
\hline 103-Not enabled & -5.93035 & 02506 & 4.48515 & 0.3685 & -1.43530 & 10000 \\
\hline 103-Teaching away & -10.4409 & 0.4506 & 24054 & 0,07 & -315102 & 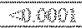 \\
\hline 103-Unexpected results & -59126 & 10000 & -18982 & $0015 ?$ & 2456 ? & 6nony \\
\hline \multirow{2}{*}{ Rejection reasons/OA } & \multirow{2}{*}{$x^{2}$} & \multirow{2}{*}{ p-value } & \multicolumn{3}{|c|}{ Graups } & \\
\hline & & & Slow & Ave & Fast & \\
\hline 103-131 declaration & 8.2101 & 0.0165 & $\mathbf{A}$ & $\mathrm{A} / \mathrm{B}$ & B & \\
\hline 103-132 declaration & 22.2240 & $<0.0001$ & $\mathbf{A}$ & $B$ & B & \\
\hline 103-Not enabled & 3.2750 & 0.1945 & A & $A$ & $A$ & \\
\hline 103-Teaclingg away & 23.8364 & 0.0001 & A & $B$ & B & \\
\hline 103-Unexpected results & 14.7353 & 0.0006 & $\mathbf{A}$ & $\mathrm{B}$ & E & \\
\hline
\end{tabular}

7. 35 U.S.C. $§ 103$ - Prior Art Not Enabled/No Motivation to Modify Traversal Strategy

Applicants may attempt to traverse an obviousness rejection by arguing that the prior art is not enabled. The basic idea behind this traversal strategy is that the disclosure provided in the prior art cannot be produced without undue experimentation. Usually, applicants argue that merely naming or describing the subject is not enough and that a person of ordinary skill in the art could not have combined the reference's description of the invention with their own knowledge to make the claimed invention. ${ }^{101}$

As a general matter, prior art references are presumed to be operable. ${ }^{102}$ This default rule is unsurprising because most prior art references are either patents or patent applications that must overcome the enablement requirement. These arguments are especially difficult to make against an obviousness rejection because even if a reference discloses an inoperative device, it is prior art for all that it teaches. ${ }^{103}$

101 See id. § 2121.01; see also Elan Pharm., Inc. v. Mayo Found. for Med. Educ. \& Research, 346 F.3d 1051 (Fed. Cir. 2003); see also In re Donohue, 766 F.2d 531 (Fed. Cir. 1985).

102 See MPEP, supra note 13, § 2121; see also In re Antor Media Corp., 689 F.3d 1282, 1289 (Fed. Cir. 2012).

103 See MPEP, supra note 13, $\S 2121$; see also Beckman Instruments, Inc. v. LKB Produkter AB, 892 F.2d 1547, 1551 (Fed. Cir. 1989). 
Thus, "a non-enabling reference may qualify as prior art for the purpose of determining obviousness under [Section] 103."104

As an initial matter, both the "prior art not enabled" and "no motivation to modify" arguments occur at very low frequencies in this dataset. ${ }^{105}$ Neither of these traversal strategies employed by applicants significantly differs between slow, average, or fast examiners. Accordingly, there is no significant difference in the use of these arguments in the obviousness context.

\section{F. Implications and Possible Solutions}

The goal of any patent examination process is to be fair, transparent, and consistent with the rules of patentability. As an aspirational goal, this is fraught with trials and tribulations, many of which are outside the control of both patent examiners and applicants. This Article makes no normative judgment as to the "optimal" or "ideal" allowance rate. Each patent application must be adjudicated on its own merits. With that said, this and previous studies show that the system falls woefully short of satisfying any "ideal" allowance rate. ${ }^{106}$ Currently, the system is such that an applicant's ability to obtain a patent may be tied to who they receive as an examiner.

There are, however, arguments for adjusting the aggregate allowance rate both up or down. Commentators who worry about granting "low quality" patents discuss mechanisms to enhance rejection rates, strengthen post-grant review and IPRs, or create a two-tier patent system. ${ }^{107}$ In contrast, other commentators worry that the allowance rate is too low and fear that examiners are rejecting "high-quality" patents; they thus wish to develop mechanisms to enhance allowance rates using strategies such as the use of continuation or RCE practice. ${ }^{108}$

This Article argues that behaviors on both extremes can harm the patent system. At its core, patent prosecution is a negotiation between the examiner and the applicant. An applicant's ability to obtain a patent should not be tied to the random assignment of a "hard" or "easy"

\footnotetext{
104 Symbol Techs., Inc. v. Opticon, Inc., 935 F.2d 1569, 1578 (Fed. Cir. 1991).

105 See infra Figure 6; see also infra Table 5.

106 See Tu, Luck/Unluck of the Draw, supra note 1, at 14; see also Tu, Three New Metrics for Patent Examiner Activity, supra note 1; see also JAMES BESSEN \& MICHAEL J. MEURER, PATENT FAILURE: HOW JUDGES, BUREAUCRATS, AND LAWYERS PUT INNOVATORS AT RISK (2009).

107 See Doug Lichtman \& Mark A. Lemley, Rethinking Patent Law's Presumption of Validity, 60 STAN. L. REV. 45 (2007), http:/www.stanfordlawreview.org/wp-content/uploads/sites/3/2010/04/ LichtmanLemley pdf [https://perma.cc/4CB5-HR7U] (arguing for the creation of a two-tiered system of patent validity); see also Mark Lemley et al., What to Do about Bad Patents?, REG., Winter 2005-2006, at 10, 12-13, https:/www.immagic.com/eLibrary/ARCHIVES/GENERAL/ STANFORD/S051208L.pdf [https://perma.cc/Z4F9-8352].

108 See Deepak Hegde et al., Quick and Dirty Patents (Jan. 5, 2020) (unpublished manuscript) (on file with SSRN), https://mgmt.wharton, upenn.edu/wp-content/uploads/2020/01/Quick-And-DirtyPatents.pdf [https://perma.cc/JJT8-SYV3] ("[Q]uick and dirty, rather than slow and thorough, patents maximize both inventor rewards and positive externalities to rivals.").
} 
examiner. Accordingly, it is important to implement strategies that bring low volume examiners more in line with average volume examiners by creating disincentives for bad rejections. Similarly, it is important to implement strategies that bring high volume examiners more in line with average volume examiners by creating procedures for reviewing bad allowances.

1. Target Examiners Who Deviate Drastically from the Norm for Enhanced Review by Quality Assurance

From these data, it can be seen that low volume examiners receive more missing elements and teaching away type arguments against anticipation and obviousness rejections. In contrast, high volume examiners have a disproportionate number of first action allowances. Both of these behaviors may be harming the consistent and fair application of the patentability rules. Accordingly, examiners who have a high number of first action allowances, or a high rejection rate combined with an applicant's use of specific arguments such as missing element(s) and/or teaching away, should be flagged more for Quality Assurance. A second pair of eyes can be used to review examiners who are making bad rejections or bad allowances.

If Quality Assurance determines that there is an error in either the rejection or the allowance, then perhaps one remedy would be to deduct counts. An additional remedy would be to require the examiner to attend specialized training in proper prior art rejections. Furthermore, if the examiner is a junior examiner without signatory authority, perhaps a further remedy would be to require the primary examiner who $i s$ working with the junior examiner to create a remediation plan.

\section{Deduct Counts for Bad Rejections and Add Counts for Difficult Applicants}

As argued above, examiners are clearly incentivized by the count system. Accordingly, one of the easiest ways to modify behavior is to modify the count system. One quick and easy way to disincentivize "bad" rejections is to deduct the counts associated with these poor rejections so that the examiners who make them must internalize their mistake. The loss attention effect may also play a role in helping examiners be more careful about making "bad" rejections. ${ }^{109}$

109 Loss attention posits that individuals will allocate more attention to a task when it involves losses than when it does not involve losses. See Eldad Yechiam \& Guy Hochman, Losses as Modulators of Attention: Review and Analysis of the Unique Effects of Losses Over Gains, 139 PSYCHOL. BULL. 497 (2013); see also Daniel Kahneman \& Amos Tversky, Prospect Theory: An Analysis of Decision Under Risk, 47 ECONOMETRICA 263 (1979), https://www.uzh.ch/cmsssl/suz/ dam/jcr:00000000-64a0-5b lc-0000-00003b7ec704/10.05-kahneman-tversky-79.pdf [https:// perma.cc/HR2C-KCKD] 
There are many situations where an examiner may make a legitimate mistake in understanding or applying the law. Additionally, there are many situations where the law may not be clear when applied to a specific application. Deduction of counts should not occur in these cases. Deduction of counts should only occur in clear cases where a pattern of gamesmanship or erroneous rejections throughout the prosecution history is unveiled.

Deduction of count(s) should be a sua sponte remedy given by: Quality Assurance at the PTO (before the patent issues), the PTAB, and/or the Federal Circuit. Applicants should not be able to request count deduction as a remedy for erroneous rejections. The fear is that applicants may try to leverage perceived "bad" rejections as a bargaining chip to remove counts to get the examiner to allow the case. ${ }^{110}$

On the other side of this coin is when applicants prolong prosecution by offering a deluge of illegitimate arguments designed simply to "wear down" the examiner. ${ }^{111}$ One solution to this problem may be to allow the examiner to impose a shortened statutory response period that is less than the standard three months. ${ }^{112}$ This would force the applicant to internalize the bad argument by paying more for any extensions of time. This might be especially appealing when the arguments made by the applicant are repetitive and put forward solely to delay prosecution. ${ }^{113}$ These extensions of time fees can range from small ( $\$ 200$ for a one-month extension) to fairly large ( $\$ 3,000$ for a five-month extension).

\section{Alert Examiners When Their Issued Cases are Litigated}

Not all post-issuance litigation information is uploaded to PAIR, and examiners are not notified of events that occur post-issuance with applications that they have previously examined. As an initial matter, examiners would be professionally interested in the patents that are litigated under their watch. Additionally, this may be a learning experience for the examiners to see how the court actually dealt with a situation that the examiner may experience again. Simply alerting the

\footnotetext{
110 For most applicants, any rejection is a "bad" rejection. Accordingly, a flood of requests for count deductions may occur if applicants could petition for this type of remedy.

111 See Lemley \& Sampat, supra note 17, at 123 ("[T]he PTO has no power to finally reject a determined applicant.").

112 Allowing the examiner to petition for additional counts should not be the remedy because examiners may try to argue that every argument is repetitive. Additionally, if an argument is repetitive, then any response to that argument would also be repetitive. Accordingly, if all the work by an examiner could be duplicated in a new Office Action, then extra counts would not be justified. 113 Applicants have many reasons why they may wish to delay prosecution, such as waiting for competitors to get something to market. Once competitors have a product on the market, applicants can then narrow their claims to cover the specific product, which may make a claim more difficult to invalidate. This strategy only works if the applicant can delay prosecution long enough to await the arrival of a commercial product.
} 
examiner to the fact that one of their patents was litigated and possibly invalidated may make the examiner more careful about "bad" rejections or force the examiner to complete a more exhaustive prior art search. Creating an opportunity to understand the results and consequences of their allowances may be a good teaching tool for examiners, especially if they receive direct guidance from a written opinion from either the PTAB or the Federal Circuit.

The PTO's Post Grant Outcomes program helps examiners understand outcomes in related AIA trial proceedings.

The Post Grant Outcomes Program is a pilot program aimed to provide examiners [with] the most [relevant] post grant information from various sources, such as AIA trial proceedings before the PTAB. The goal of this program is to improve the consistency of patentability determinations in related pending patent applications by notifying examiners when they have an application related to an AIA trial proceeding, streamlining access to the contents of the AIA trial proceedings, and determining and disseminating best practices for evaluating those proceedings. ${ }^{114}$

Moreover, beginning in 2019, "a feature was added to the examination toolkit to facilitate and assist an examiner to readily access documents directly related to a pending application."115 Since the program's inception, "over 2,062 cases have been identified . . to assist examiners in their examination process by not only making access to prior art easier, but also by fostering improved patent quality." 116

To take this idea one step further, if examiners receive a notice that a patent they issued is currently undergoing litigation, it might be a worthwhile exercise to allow the examiner to write a short report/opinion defending the application or use any new information gathered from litigation to form a new rejection. This would be an internal document used only for training. To incentivize examiners to write these reports, the PTO should consider giving examiners one to two hours of time to write this opinion. One could even imagine a system where the examiner is given an additional count if the PTAB, district court, Federal Circuit, and/or Supreme Court confirms the examiner's opinion.

4. Bifurcation of the Patent Searching and the Office Action Writing Process

The main goal of this proposed solution is to get the best prior art in front of the examiner as quickly as possible. Providing the examiner

114 U.S. PATENT \& TRADEMARK OFFICE, supra note 5 , at 54.

$115 \mathrm{Id}$.

$116 \mathrm{Id}$. 
with the best prior art at the earliest stage of prosecution should speed up the examination process, increase the efficiency of prosecution, and improve prosecution quality.

As an initial matter, the PTO has tangentially addressed this issue by creating a pilot program called the "Access to Relevant Prior Art Initiative" to help get some relevant prior art to examiners. ${ }^{117}$ However, this program focuses only on the references cited in related parent applications. The main purpose of this program is to help applicants comply with the duty of disclosure, and it is not designed to help discover new prior art. Nonetheless, this is one step in the right direction to get relevant prior art in front of the examiner. The program was designed to create a single list of references, combining those references cited in an application and those from related U.S. parent applications. ${ }^{118}$ These references would be automatically imported into a file for the examiner's review. The scope of this program, however, is limited because it only includes references cited in the instant application (by the applicant and examiner) and imported references from immediate U.S. parent applications (cited by the applicant and examiner). Importantly, it specifically does not include references cited by third parties. Additionally, it does not include any "new" references for the instant application.

One issue that may be facing examiners is simply a lack of a deep understanding and knowledge of the technical field. As examiners spend more years at the PTO, they necessarily become more removed from their research or laboratory backgrounds, and thus may not be as familiar with the current literature. This solution attempts to address this issue by creating a group of examiners who only focus on searching for prior art. Therefore, this solution calls for a two-step process: first acquiring the best prior art references, and then delivering the most relevant prior art references into the hands of an examiner who specializes in drafting Office Actions.

This solution calls for a bifurcation of the labor involved in the patent examination process. Specifically, this division of labor would create two distinct examination cores: (1) a first group that specializes in prior art searching (searching examiners), and (2) a second group that focuses on drafting Office Actions (drafting examiners). Specialization would allow searching examiners time to keep up with the current literature and hone their ability to create effective searches. Additionally, specialization would allow drafting examiners to keep up with the current

117 See Access to Relevant Prior Art Initiative, USPTO: PATENTS, https://www.uspto.gov/patentsgetting-started/access-prior-art-project [https://perma.cc/P7PY-5TGU].

118 See id.; see also David Hricik, Access to Prior Art Initiative of the USPTO to Ease Importation of Prior Art References from Parent Cases, PATENTLY-O (Feb. 3, 2020), https://patentlyo.com/ hricik/2020/02/initiative-importation-references.html [https://perma.cc/652D-MH5F]. 
legal changes and refine their proficiency in drafting clear, concise, and appropriate rejections.

Searching examiners would specialize in and have sole responsibility for completing the prior art search. Thus, searching examiners would have the ability to spend time specializing in creating targeted keyword searches for a variety of inventions within the same art unit or workgroup. Additionally, these examiners would have a deeper knowledge of the current state of the art, as well as the most relevant databases to search.

It should be noted that the PTO has already created programs to enhance the examiner's subject matter expertise. For example, the Patent Examiner Technical Training Program (PETTP) provides a forum for industry and academic experts to provide technical training to examiners. Additionally, the Site Experience Education (SEE) program allows commercial, industrial, and academic institutions to host patent examiners for site visits. Both programs help keep examiners abreast of the most recent developments in innovation in their respective fields.

Drafting examiners would specialize in drafting Office Actions based, in part, on the results of the prior art search generated by the searching examiners. Drafting examiners would specialize in understanding and applying the relevant patent law and would have sole responsibility for composing the Office Action and applying the relevant patentability rules. Thus, drafting examiners would have time to understand and research current trends, case law, and changes in patent law. Additionally, drafting examiners could spend more time obtaining the writing skills necessary to convey clear rejections. The PTO is already addressing some of these issues by requiring all examiners to receive training in areas of the law that are not currently well developed. ${ }^{119}$ For example, the PTO required patentable subject matter. ${ }^{120}$ Notably, "[a]lthough all patent examiners [were mandated to] receive[] training, those examiners that were most impacted by the guidance [were required to] receive[] more in-depth training and ... additional follow-on training later in the year." 121

One advantage of this division of labor is that the examiner would be limited to a universe of prior art when determining which references to use when rejecting the application. This would prevent examiners from bringing in new but redundant art when making a rejection. This Article recognizes that the searching examiner would have to complete a new search, which may change the universe of available prior art if the claims were altered during prosecution. However, this might still be

119 See U.S. PATENT \& TRADEMARK OFFICE, supra note 5, at 55.

$120 \mathrm{Id}$.

$121 \mathrm{Id}$. 
advantageous in an obviousness setting because the drafting examiner might be required to use at least one new reference found by the searching examiner after a claim amendment.

There are several limitations involved with this solution. Foremost is a delay in prosecution caused by running the application through two steps at the patent office. Additionally, bifurcation may lead to a diminishment of the drafting examiners' knowledge of the relevant prior art. This diminishment of knowledge in the field may lead to more difficulty for the drafting examiner to gauge the novelty or nonobviousness of the invention if they are unable to understand how the claimed invention sits within the larger technological field. Finally, with particularly complex inventions, increased search costs may be experienced when the invention is incorrectly classified because the searching examiner may have to create new search terms or a new search strategy when dealing with an unfamiliar technology (or simply transfer the search to a different art unit).

\section{CONCLUSION}

Currently, an applicant's ability to obtain a patent in a reasonable amount of time is, in large part, linked to the examiner who is assigned to the application. This Article shows that the type of examiner assigned to the case (whether a low, average, or high volume examiner) will affect the application's time in prosecution. The duration of patent prosecution can vary, on average, between about 1.5 and six years, depending on the examiner type. Unnecessary delays in prosecution can result in increased prosecution costs and attorneys' fees, as well as lost opportunities for businesses that may need a patent to obtain venture capital funding or to take advantage of other time-dependent market prospects.

Low volume examiners are making more obviousness and anticipation rejections based on more prior art and facing more applicant arguments that show that the examiner is misunderstanding either the prior art or claimed invention. Conversely, high volume examiners may be issuing patents too quickly without a thorough review of the prior art. The goal of the patent examination system should be to be fair, transparent, and to have consistent application of the rules of patentability. This Article shows that examiners are not consistent when applying the novelty and obviousness standards. Both types of examiners may be harming innovation in two completely different ways.

As previously stated, there is no "optimal" grant rate. However, it is possible to glean at least a "standard" grant rate by looking at the grant rate from the "average" examiner. This Article argues for enhanced review of examiners who are several standard deviations from the mean (both low and high volume examiners). Recognizing that both low and 
high volume examiners are most likely maximizing counts, this Article proposes some relatively easy solutions to dull gamesmanship-for example, removing counts for clearly bad rejections or giving more time or counts to examiners who write detailed PTAB appeal responses. Finally, this Article proposes bifurcating the examination core into two types of examiners: searching examiners, who function to find relevant prior art, and drafting examiners, who function to apply the prior art to a well-written Office Action. 
APPENDIX A1.

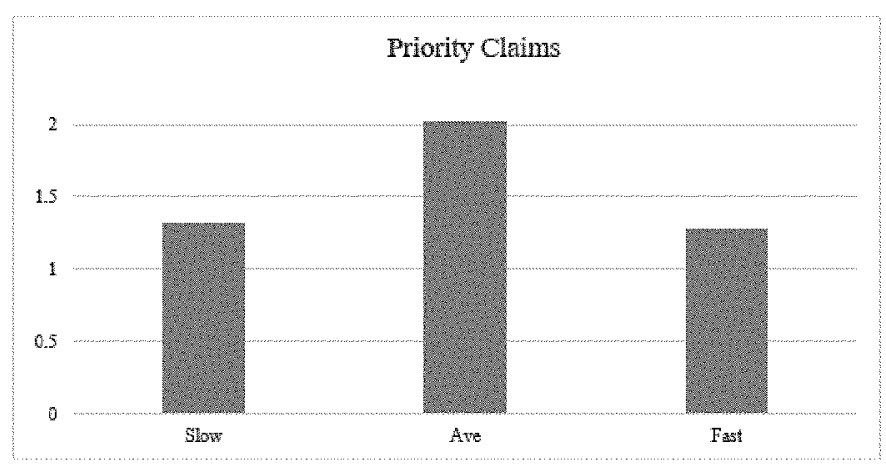

APPENDIX A2.

\begin{tabular}{|c|c|c|c|c|c|c|}
\hline & \multicolumn{2}{|c|}{ Tast-Ave } & \multicolumn{2}{|c|}{ Aye-Slow } & \multicolumn{2}{|c|}{ Tast-Slow } \\
\hline & SMD & p-value & SMD & p-value & SMD & p-value \\
\hline \multirow[t]{3}{*}{ Priority } & 371308 & 0.0966 & 28772 & 8017 & 83437 & 10000 \\
\hline & \multirow{2}{*}{\multicolumn{2}{|c|}{$x^{2}$}} & , & \multicolumn{3}{|c|}{ Groups } \\
\hline & & & p-tyane & Slow & we & \\
\hline Priority & \multicolumn{2}{|c|}{11.0610} & 0.0040 & B & A & \\
\hline
\end{tabular}

APPENDIX B1.

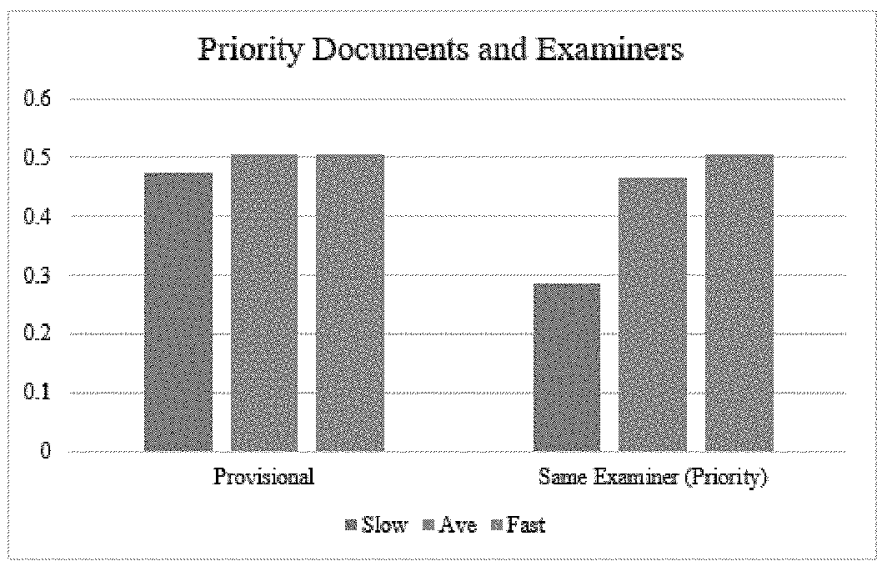

APPENDIX B2.

\begin{tabular}{|c|c|c|c|c|c|c|}
\hline & \multicolumn{2}{|c|}{ Slow/Ave } & \multicolumn{2}{|c|}{ Slow Fast } & \multicolumn{2}{|c|}{ Ave/Tast } \\
\hline & $\begin{array}{l}\text { Odds } \\
\text { Ratio }\end{array}$ & p-value & $\begin{array}{l}\text { Odds } \\
\text { Ratio }\end{array}$ & p-ralue & $\begin{array}{l}\text { Odds } \\
\text { Ratio }\end{array}$ & p-value \\
\hline Provisional & 0.857902 & 0.6728 & 0.905660 & 0.7256 & 1.02 & 09440 \\
\hline \multirow[t]{3}{*}{$\begin{array}{l}\text { Same Examiner } \\
\text { (Priority) }\end{array}$} & $0.46 \% 7 \%$ & anot? & 7) 36508 & Q6012 & 0.83624 & 0.5265 \\
\hline & \multicolumn{4}{|c|}{ Groups } & & \\
\hline & Slow & & Ave & Fast & & \\
\hline Provisional & A & & A & $\mathbf{A}$ & & \\
\hline Same Examiner (Priority) & B & & A & A & & \\
\hline
\end{tabular}


APPENDIX C1.

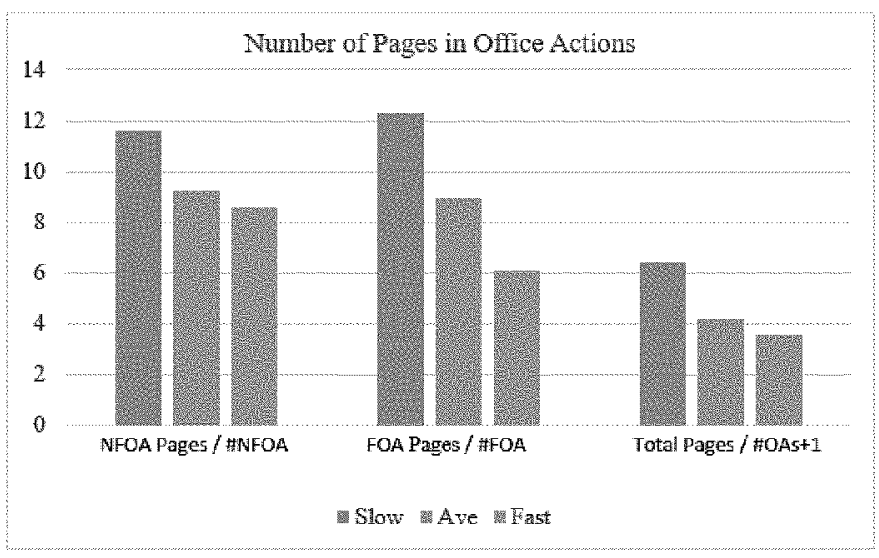

APPENDIX C2.

\begin{tabular}{|c|c|c|c|c|c|}
\hline & \multirow{2}{*}{$x^{3}$} & \multirow{2}{*}{ p-value } & \multicolumn{3}{|c|}{ Groups } \\
\hline & & & Slow & Ave & Fast \\
\hline $\begin{array}{l}\text { NFOA } \\
\text { Puges/HNFOAs }\end{array}$ & 23.9543 & -0.0001 & $\mathbf{A}$ & B & $\mathrm{B}$ \\
\hline $\begin{array}{l}\text { FOA } \\
\text { Puges/AFOAs }\end{array}$ & 21.8388 & $<0.0001$ & A & B & $B$ \\
\hline $\begin{array}{l}\text { Tatal } \\
\text { Pages/4OAs+1 }\end{array}$ & 48.9894 & $=0.0001$ & A & $\mathrm{B}$ & B \\
\hline
\end{tabular}

APPENDIX D.

Citation types for 102 (a), (g) or (e) Rejections par Office Action

\begin{tabular}{|l|l|l|l|l|l|}
\hline & $\begin{array}{l}\text { US } \\
\text { Patent }\end{array}$ & $\begin{array}{l}\text { US Patent } \\
\text { Application }\end{array}$ & $\begin{array}{l}\text { Foreign } \\
\text { PatentApplication }\end{array}$ & $\begin{array}{l}\text { Privied } \\
\text { Publication }\end{array}$ & $\begin{array}{l}\text { Total } \\
\text { References }\end{array}$ \\
\hline $\begin{array}{l}\text { Slow } \\
\text { Examiners }\end{array}$ & 0.208 & 0.0693 & 0.0198 & 0.109 & 0.356 \\
\hline $\begin{array}{l}\text { Axerage } \\
\text { Examiners }\end{array}$ & 0.089 & 0.109 & 0.0297 & 0.0296 & 0.215 \\
\hline $\begin{array}{l}\text { Fast } \\
\text { Examiners }\end{array}$ & 0 & 0.0204 & 0.020 & 0.0102 & 0.0408 \\
\hline
\end{tabular}

APPENDIX E.

Citation types for $102(\mathrm{~b})$ Rejections per Office Action

\begin{tabular}{|c|c|c|c|c|c|}
\hline & $\begin{array}{l}\text { US } \\
\text { Patent }\end{array}$ & $\begin{array}{l}\text { US Patent } \\
\text { Application }\end{array}$ & $\begin{array}{l}\text { Foneign } \\
\text { Patent/Application }\end{array}$ & $\begin{array}{l}\text { Printed } \\
\text { Poblication }\end{array}$ & $\begin{array}{l}\text { Total } \\
\text { References }\end{array}$ \\
\hline $\begin{array}{l}\text { Slow } \\
\text { Examiners }\end{array}$ & 0.228 & 0.0297 & 0.198 & 0.310 & 0.723 \\
\hline $\begin{array}{l}\text { Awerage } \\
\text { Examiners }\end{array}$ & 0218 & 0.0891 & 0.0396 & 0.356 & 0.624 \\
\hline $\begin{array}{l}\text { Fist } \\
\text { Examiners }\end{array}$ & 0.133 & 0.0306 & 0.0816 & 0.245 & 0.490 \\
\hline
\end{tabular}




\section{APPENDIX F.}

Citation types for 103 Rejections per Office Action

\begin{tabular}{|l|l|l|l|l|l|}
\hline & $\begin{array}{l}\text { US } \\
\text { Patemt }\end{array}$ & $\begin{array}{l}\text { US Patent } \\
\text { Applisation }\end{array}$ & $\begin{array}{l}\text { Foreign } \\
\text { Patent/Application }\end{array}$ & $\begin{array}{l}\text { Printed } \\
\text { Publication }\end{array}$ & $\begin{array}{l}\text { Total } \\
\text { References }\end{array}$ \\
\hline $\begin{array}{l}\text { Slow } \\
\text { Examinerg }\end{array}$ & 1.158 & 0.208 & 0.287 & 0.381 & 2.38 \\
\hline $\begin{array}{l}\text { Averase } \\
\text { Examinerg }\end{array}$ & 0.514 & 0.287 & 0.178 & 0.743 & 1.64 \\
\hline $\begin{array}{l}\text { Fast } \\
\text { Examiners }\end{array}$ & 0.153 & 0.0408 & 0.0816 & 0.0612 & 0.397 \\
\hline
\end{tabular}

